\title{
An Intercomparison of Three Snow Schemes of Varying Complexity Coupled to the Same Land Surface Model: Local-Scale Evaluation at an Alpine Site
}

\author{
AARON BOONE \\ Météo-France/Centre National de Recherche Météorologique, Toulouse, France \\ PIERRE ETCHEVERS \\ Météo-France/Centre Etudes de la Neige, Grenoble, France
}

(Manuscript received 21 August 2000, in final form 23 February 2001)

\begin{abstract}
The Interactions between Soil, Biosphere, and Atmosphere land surface scheme is currently used coupled both to atmospheric models and to a distributed hydrological model. There are two snow-scheme options available for hydrological modeling: the baseline force-restore approach, which uses a composite snow-soil-vegetation energy budget and a single snow layer; and a multilayer detailed internal-process snow model. Only the forcerestore method is routinely used in atmospheric modeling applications. Recent studies have shown that hydrological simulations for mountainous catchments within the Rhone basin, France, are significantly improved using the detailed snow scheme. The main drawback is that the scheme is computationally expensive, and it is not currently feasible for routine application in atmospheric models. For these reasons, a third new intermediatecomplexity scheme has been developed that includes certain key physical processes from the complex model for improved snowpack realism and hydrological depiction while attemping to keep computational requirements similar to those of the simple default scheme. In the current study, the new scheme is described, evaluated, and compared with the results from the two other schemes at a local scale at an alpine site located within the Rhone basin for two contrasting (weather) years. All schemes are able to model the basic features of the snow cover with similar errors averaged over the 2-yr period; however, there are important differences on shorter timescales. When compared with the more complex scheme, it was found that differing surface energy budget parameterizations (turbulent transfer, albedo) were the cause for the largest differences in total snowpack snow water equivalent (SWE) simulated by the models. When compared with the simple scheme, the ability for the intermediate model to simulate snow ripening resulted in the largest differences in simulated SWE and snow temperature during melt and runoff.
\end{abstract}

\section{Introduction}

The snow cover is known to have a profound effect on the land surface primarily through modification of the surface albedo, roughness, and the insulating capacity of the snow. Snow coverage varies greatly in both time and space and modulates the radiative fluxes and the fluxes of heat, momentum, and moisture between the surface and atmosphere. The hydrologic cycle also is influenced, because a large component of the precipitation enters the soil significantly lagged in time because of storage by the snow cover.

Soil-vegetation-atmosphere transfer (SVAT) schemes aim to model the physics at the soil-vegetation-snowatmosphere interface. Three general model complexity classifications can be used to describe the snow com-

Corresponding author address: Aaron A. Boone, Météo-France, CNRM/GMME/MC2, 42 avenue Coriolis, 31057 Toulouse Cedex, France.

E-mail: boone@cnrm.meteo.fr ponent of SVAT schemes that are in use by the atmospheric research community. 1) The first class consists of relatively simple so-called force-restore schemes in which the snow is modeled using composite snow-soil layer(s) (Pitman et al. 1991; Douville et al. 1995a; Yang et al. 1997). There is also another group of schemes that falls into this relatively simple class, which uses a single explicit snow layer to differentiate the thermal properties and surface fluxes of the snow cover from that of the soil (e.g., Verseghy 1991; Slater et al. 1998; Sud and Mocko 1999). 2) The second class of schemes consist of detailed internal-snow-process schemes such as those of Anderson (1976), Brun et al. (1989), Jordan (1991), Bader (1992), and Lehnings et al. (1998). These models use multiple layers with a relatively fine vertical resolution and have detailed physical parameterization schemes. Their use in atmospheric models, however, has been limited by their relatively large computational expense. 3 ) A third class of so-called intermediate-complexity schemes are based on the internal-snow-process (class 2) models. However, they use simplified versions of the 
physical parameterization schemes describing what are deemed to be the most important processes from the complex models and the minimum number of layers required to resolve the large thermal and density gradients within the snow cover (Loth et al. 1993; Lynch-Stieglitz 1994; Sun et al. 1999). The intended application of these schemes is for full coupling within atmospheric models.

Several snow-scheme intercomparison studies have recently been undertaken to address issues related to the current state of snow modeling used by the atmospheric research community. Schlosser et al. (2000) intercompared 18-yr simulations of a microclimate by 21 SVAT models that represented the full range of snow scheme complexity for a cold continental region in Russia under the auspices of the Project for the Intercomparison of Land-Surface Parameterization Schemes (PILPS; Henderson-Sellers et al. 1995). They found that considerable model variability exists for the snow simulations, especially with respect to snow ablation, which is of critical importance to both predicted atmospheric fluxes and the hydrologic cycle. Essery et al. (1999) compared simulations of snow at an alpine micrometeorological site by two climate model snow schemes, a model for hydrological forecasting and an operational avalanche prediction model. They found the models simulated similar snow cover durations but differed with respect to the timing and amount of peak snow mass and the temporal distribution of runoff. Jin et al. (1999) examined simulations of snow ablation by three snow schemes of varying complexity in terms of climate model applications. They found good agreement for seasonal timescales among the snow models in terms of predicted snow surface fluxes, temperature, and snow water equivalent, but certain simulation deficiencies were discovered with respect to the least-complex (class 1) forcerestore scheme on a diurnal timescale, primarily due to the neglect of liquid water retention by the snow cover. The intermediate (class 2 ) scheme generally was able to simulate the basic features of the snow cover well in comparison with a much more complex internal process (class 3) model for the timescales considered.

This study differs from the aforementioned snow scheme intercomparison studies in one main respect: all three snow schemes use the same SVAT, that is, the same vegetation, hydrologic, and soil thermal parameterization schemes. The simple snow (or class 1) scheme used in this study is represented by the baseline Interactions between Soil, Biosphere, and Atmosphere (ISBA) force-restore model (herein referred to as ISBAFR). This scheme has been primarily developed for large-scale atmospheric models (Douville et al. 1995b). The highly detailed (class 2) scheme is represented by the "CROCUS" snow model (Brun et al. 1989, 1992), which is used for operational avalanche forecasting. The coupled ISBA-CROCUS model (simply referred to as CROCUS herein; Etchevers 2000) has primarily been developed for two reasons: 1) to provide a dynamic lower soil boundary condition for the snowpack and 2) for applications in which the snow is a major component of the hydrologic cycle. The intermediate or class-3 snow scheme, called ISBA-ES (ISBA explicit snow), has been developed in an attempt to understand better the snow model differences and which processes should be modeled for atmospheric and hydrological applications while keeping computational cost to a minimum.

In the current study, ISBA-ES is presented along with concise descriptions of the ISBA-FR and CROCUS schemes. It is tested and evaluated in so-called offline mode, which means that the surface schemes are driven using standard atmospheric data and observations and there is no coupling with an atmospheric model. Data for two contrasting snow seasons from a micrometeorological site located in the French Alps within the Rhone River basin are utilized. ISBA-ES local-scale simulation results are evaluated and compared with those of ISBA-FR and CROCUS. Model differences that give rise to the most important simulation differences are discussed, and some basic sensitivity studies are done to help to explain some of the most significant model simulation differences.

\section{General scheme overview}

\section{a. The ISBA land surface model}

The ISBA model is based on the force-restore approach of Deardorff $(1977,1978)$. The baseline model is described in detail in Noilhan and Planton (1989) and Noilhan and Mahfouf (1996). In brief, a single soilvegetation-snow surface temperature relationship is used to calculate the surface energy budget, and there is a single restore temperature. There are surface hydrologic reservoirs for the liquid precipitation intercepted by the vegetation canopy, the snow cover, and the superficial soil moisture. The subsurface soil column is divided into two subsurface soil moisture reservoirs consisting of a root-zone layer and a subroot-zone layer (Boone et al. 1999), and soil freezing is taken into account (Boone et al. 2000). The purpose of the ISBA scheme is to calculate the surface radiative, heat, momentum, and moisture exchanges with the atmosphere and the components of the near-surface hydrological budget.

\section{b. ISBA-FR snow scheme}

The ISBA-FR snow scheme has been tested at the local (single point) scale for micrometeorological sites located in Russia, the French Alps, and Japan (Douville et al. 1995a; Schlosser et al. 2000). It has also been evaluated in offline mode using remote sensing data following the Global Soil Wetness Project experimental design (Dirmeyer 1997) at the global scale (Etchevers et al. 1999). Climate sensitivity experiments have been done using this scheme to test the impact of an anomalous Eurasian snow cover (Douville and Royer 1996) 
TABLE 1. Summary of basic snow scheme differences. CPU ratio refers to the approximate ratio of the computational time for each scheme to that of ISBA-FR for the same simulation. The remaining symbol definitions can be found in the text. Scheme complexity increases from left to right.

\begin{tabular}{llll}
\hline \hline \multicolumn{1}{c}{ Parameterization } & \multicolumn{1}{c}{ ISBA-FR } & \multicolumn{1}{c}{ ISBA-ES } & CROCUS \\
\hline$C_{H}$ (turbulent transfer) & Louis $(1979): f\left(R_{i}\right)$ & Louis $(1979): f\left(R_{i}\right)$ & $f\left(R_{i}>0\right)=1$ or fixed \\
$z_{0}$ (snow roughness) & Effective & Effective & $10^{-3}-10^{-2} \mathrm{~m}$ \\
$\Lambda_{s}$ (thermal conductivity) & Yen $(1981)$ & Anderson $(1976)$, Sun et al. $(1999)$ & Modified Yen $(1981): \geq 0.13 \mathrm{~W} \mathrm{~m}^{-1} \mathrm{~K}^{-1}$ \\
$\rho_{\text {new }}($ snowfall density) & Constant & $f\left(T_{a}, V_{a}\right)$ & $f\left(T_{a}, V_{a}\right)$ \\
Explicit metamorphism & No & No & Yes \\
Settling & Time constant & Anderson $(1976): f\left(\sigma_{s}, T_{s}, \rho_{s}\right)$ & Brun et al. $(1989): f\left(\sigma_{s}, T_{s}, \rho_{s}\right)$ \\
$D_{s 1}$ (surface thickness) & $0.03 \leq 0.05 \mathrm{~m}$ & $0.0025 \leq 0.05 \mathrm{~m}$ & $\geq 0.005 \mathrm{~m}$ \\
$\alpha_{n}$ (snow albedo) & Time constants & Time constants & Grain size, density \\
No. of layers & 1 & 3 & $\leq 50$ \\
$W_{l \text { max }}$ (liquid capacity) & 0 & $3 \%-10 \%$ mass & $5 \%$ pore volume \\
Ripening & No & Yes & Yes \\
$R_{g}$ transmission & No & Single spectral band & Multiple bands \\
Snow-soil heat flux & Implicit: none when $p_{n}=1$ & Explicit & Explicit \\
$P_{l}$ (rain heat flux $)$ & No & Yes & Yes \\
CPU ratio (to ISBA-FR) & 1 & 2 & 5 \\
\hline
\end{tabular}

and of boreal deforestation (Douville and Royer 1997). More recently, it has been coupled to the Modél Couplé de l'Ecole des Mines de Paris (MODCOU) distributed hydrological model (Ledoux et al. 1989) and used to simulate the hydrological cycle for the Rhone basin (Etchevers 2000; Habets et al. 1999).

There are two prognostic state variables used for a single-layer snow pack; the snow water equivalent (SWE) and the average snow cover density. A final snow prognostic variable is used to model the surface snow albedo. The heat content of the snow is implicitly represented by the composite soil-vegetation-snow surface and restore prognostic temperatures.

\section{c. CROCUS scheme}

CROCUS has primarily been developed for the detailed study of the snowpack evolution at a particular location, and for operational avalanche prediction. It has been extensively validated at the local scale for sites located in the French Alps (e.g., Brun et al. 1989, 1992; Martin and Lejeune 1998). Like ISBA-FR, CROCUS participated in the PILPS Valdai experiment (Schlosser et al. 2000), was run in offline mode at the global scale (Etchevers et al. 1999), and has been coupled to MODCOU (Etchevers 2000). In addition, CROCUS has also been tested coupled to a global climate model (Brun et al. 1997)

CROCUS models the snow stratigraphy using a onedimensional finite-element grid. Each snow layer is described by the thickness, temperature, dry density, liquid water content, grain types (dendricity, spericity, size, and age), and a historical variable that indicates whether there was liquid water or faceted crystals in the layer. The model is driven by observed, analyzed, or modeled meteorological variables at the snow surface.

\section{d. ISBA-ES scheme}

The purpose of the new scheme is for use in coupled SVAT-hydrological model applications and eventual coupling with atmospheric models. The model is based on similar such schemes described by Kondo and Yamazaki (1990), Loth et al. (1993), Lynch-Stieglitz (1994), and Sun et al. (1999), of which the latter three are designed for use in atmospheric climate models. There are three variables saved at each time step that are used to describe the state of the snow for three layers: the heat content (or specific enthalpy), the snow density, and thickness. The snow albedo represents a fourth prognostic variable. The ISBA-ES scheme is presented in the following section, along with concise descriptions of the corresponding elements of the ISBA-FR and CROCUS schemes. Basic scheme differences are summarized in Table 1. The solution procedure for ISBAES is outlined in the appendix.

\section{Snow-scheme physics}

\section{a. Mass balance}

The mass conservation equation for the total snowpack is expressed for ISBA-ES as

$$
\partial W_{s} / \partial t=\left(P_{n}+p_{n} P_{l}-R_{l N}-E_{\mathrm{sn}}\right),
$$

where $W_{s}$ corresponds to the total snowpack SWE, which can also simply be expressed as the product of the average snowpack density $\rho_{s}$ and total snow depth $D_{s}$. Here, $E_{\mathrm{sn}}$ represents the combined evaporation and sublimation rate, $P_{n}$ represents the snowfall rate, and the rain rate is $P_{l}$. The fractional snow-covered area FSCA varies between zero and unity and is represented by $p_{n}$. The product $p_{n} P_{l}$ represents the portion of the total rainfall that is intercepted by the snow surface; the remaining rainfall is assumed to be intercepted by the snow-free soil and vegetation surfaces. The snow-runoff rate $R_{I N}$ is defined as the rate at which liquid water leaves the base of the snow cover. Here, $t$ is time. All rates are expressed in kilograms per meter squared per second.

The mass balance equation for CROCUS is the same, but in ISBA-FR the liquid precipitation source term $p_{n} P_{l}$ 
is dropped because the snow liquid holding capacity is neglected. There is no freezing of liquid water within the snowpack and all rainfall is directly available to the soil.

\section{b. Snow layering}

The number of layers in ISBA-ES is prescribed to be three, which is considered to be the minimum number of layers required to resolve adequately the snow thermal profile between the top and the base of the snow cover (Lynch-Stieglitz 1994; Sun et al. 1999; Jin et al. 1999). The snow-layer thicknesses for the uppermost two layers are defined using a scheme that is similar to that of Lynch-Stieglitz (1994):

$$
\begin{aligned}
D_{s 1}= & \delta 0.25 D_{s}+(1-\delta) D_{s 1 \max } \\
D_{s 2}= & \delta 0.50 D_{s} \\
& +(1-\delta)\left[0.34\left(D_{s}-D_{s 1 \max }\right)+D_{s 1 \max }\right] \\
& \quad\left(D_{s 2} \leq 10 D_{s 1 \max }\right),
\end{aligned}
$$

where the third layer is simply the total depth $D_{s}$ less the thickness of the first two layers. The ratios of each layer to the total depth is constant for snow depths below $0.2 \mathrm{~m}(\delta=1)$, with the highest vertical resolution at the top and base of the snowpack. The upper-layer thickness becomes constant $\left(D_{s 1 \max }\right)$ when the total depth exceeds $0.2 \mathrm{~m}(\delta=0)$, and it is prescribed to be 0.05 $\mathrm{m}$ to resolve the diurnal cycle based on an assumed thermal damping depth of snow (Dickinson 1988). In addition, the second layer is limited at $0.5 \mathrm{~m}$, because vertical gradients of heat and density are likely to be largest near the snow surface. The vertical profiles of snow mass and heat are redistributed after the grid thicknesses have been updated so as to ensure mass and heat conservation. This implies a certain degree of mixing (of mass and heat) at layer interfaces during periods of snow melt and accumulation, so that layer "memory" can be relatively short under these circumstances for relatively thin layers.

In contrast, the layering scheme of CROCUS is a "historical"-type scheme in that each layer represents a snowfall event. Layers can be added up to a maximum of 50, and the minimum thickness is constrained to be $0.005 \mathrm{~m}$. In the event that a layer does not meet certain criteria, layers with similar densities are combined (Brun et al. 1989). The ISBA-FR snow depth is simply a diagnostic variable. It has no direct bearing on the properties of the snowpack.

\section{c. Density}

The local rate of change of density (increases) due to the weight of the overlying snow and settling (primarily of new snow) is parameterized after Anderson (1976) as

$$
\frac{1}{\rho_{s i}} \frac{\partial \rho_{s i}}{\partial t}=\frac{\sigma_{s i}}{\eta_{s i}\left(T_{s i}, \rho_{s i}\right)}+\xi_{i}\left(T_{s i}, \rho_{s i}\right)
$$

where the first term on the right-hand side of Eq. (4) represents overburden (the compactive viscocity term). The pressure of the overlying snow is represented by $\sigma_{s}(\mathrm{~Pa})$, and $\eta_{s}$ is the snow viscocity ( $\left.\mathrm{Pa} s\right)$, which is an exponential function of snow temperature and density (Mellor 1964; Kojima 1967). The second term represents the thermal metamorphism (Anderson 1976), which can be significant for fresh relatively low-density snowfall $\left(\rho_{s} \leq 150 \mathrm{~kg} \mathrm{~m}^{-3}\right)$. After the newly settled/ compacted snow density has been calculated, the layer thicknesses are proportionally decreased.

The snow is compacted in CROCUS using an expression that is similar to Eq. (4) (Brun et al. 1989) but uses different parameter values. Both snow-settling schemes allow the snow to compact to densities of approximately $450-500 \mathrm{~kg} \mathrm{~m}^{-3}$. Additional density increases in ISBA-ES and CROCUS arise from compaction due to melting, infiltration of rainwater, and retention of snowmelt (discussed in a subsequent section).

The formulation used by ISBA-FR is different in that compaction is based on time constants that are assumed to take into account the aforementioned processes. It is expressed as

$$
\begin{gathered}
\rho_{s}(t+\Delta t)=\left[\rho_{s}(t)-\rho_{\max }\right] \exp \left(-\tau_{f} \Delta t / \tau\right)+\rho_{\max } \\
\left(\rho_{\min } \leq \rho_{s} \leq \rho_{\max }\right),
\end{gathered}
$$

where $\tau$ represents the period of one day, the time constant $\tau_{f}$ is fixed at a value of 0.24 (Verseghy 1991), and the maximum $\left(\rho_{\max }\right)$ and minimum $\left(\rho_{\min }\right)$ snow densities are 300 and $100 \mathrm{~kg} \mathrm{~m}^{-3}$, respectively.

The snowfall density is expressed using the expression from CROCUS in ISBA-ES as

$$
\rho_{\text {new }}=a_{\mathrm{sn}}+b_{\mathrm{sn}}\left(T_{a}-T_{f}\right)+c_{\mathrm{sn}}\left(V_{a}\right)^{1 / 2},
$$

where $T_{a}$ represents the air temperature $(\mathrm{K}), T_{f}$ is the triple-point temperature for water $(273.16 \mathrm{~K})$, and $V_{a}$ is the wind speed $\left(\mathrm{m} \mathrm{s}^{-1}\right)$. The coefficients are $a_{\mathrm{sn}}=109$ $\mathrm{kg} \mathrm{m}^{-3}, b_{\mathrm{sn}}=6 \mathrm{~kg} \mathrm{~m}^{-3} \mathrm{~K}^{-1}$, and $c_{\mathrm{sn}}=26 \mathrm{~kg} \mathrm{~m}^{-7 / 2} \mathrm{~s}^{1 / 2}$. The minimum snow density is constrained to be $50 \mathrm{~kg}$ $\mathrm{m}^{-3}$ in ISBA-ES and $30 \mathrm{~kg} \mathrm{~m}^{-3}$ in CROCUS. The ISBAFR snowfall density is constant $\left(\rho_{\min }\right)$.

\section{d. Energy balance and heat flow}

The ISBA-ES snow heat content $\left(\mathrm{J} \mathrm{m}^{-2}\right)$ for each snow layer is defined using an expression similar to that of Lynch-Stieglitz (1994) and Sun et al. (1999) as

$$
H_{s i}=c_{s i} D_{s i}\left(T_{s i}-T_{f}\right)-L_{f}\left(W_{s i}-W_{l i}\right),
$$

where $L_{f}$ is the latent heat of fusion. The snow heat capacity is defined as (Verseghy 1991) $c_{s}=c_{I} \rho_{s}$, where $c_{I}$ is the specific heat of ice. The snow-layer liquid water content $\left(\mathrm{kg} \mathrm{m}^{-2}\right)$ is represented by $W_{l}$. The snow heat content is used to allow the presence of either cold (dry) 
or warm (wet) snow. The heat content is used to diagnose the current snow temperature using Eq. (7) assuming that there is no liquid water in the snow layer $\left(W_{l}=0\right)$. If the calculated temperature exceeds the freezing point, then the temperature is set to $T_{f}$ and the liquid water content is diagnosed from Eq. (7).

Snow heat flow is along the thermal gradient, because any snowmelt or percolated water within the snow cover is assumed to have zero heat content. In addition, solar radiation decays exponentially within the snowpack as a function of depth. The layer-averaged snow temperature equation $T_{s i}$ is then expressed as

$$
c_{s i} D_{s i} \frac{\partial T_{s i}}{\partial t}=G_{s i-1}-G_{s i}-F_{s i}
$$

where $F_{s}$ represents latent heat absorbtion or release due to phase changes (between water and ice). The heat flux $G_{s}$ is simply expressed as

$$
G_{s i}=J_{s i}+Q_{s i}
$$

where the heat diffusion $J_{s}$ and radiation $Q_{s}$ flux terms are defined as

$$
\begin{aligned}
& J_{s i}= 2\left(D_{s i} \Lambda_{s i}+D_{s i+1} \Lambda_{s i+1}\right) \\
& \times\left(T_{s i}-T_{s i+1}\right) /\left(D_{s i}+D_{s i+1}\right)^{2} \\
&\left(i=1, N_{s}-1\right) \text { and } \\
& Q_{s i}= R_{g}\left(1-\alpha_{n}\right) \exp \left(-\nu_{s i} z_{i}\right) \\
&\left(i=0, N_{s}\right) .
\end{aligned}
$$

The snow thermal conductivity $\left(\Lambda_{s}: \mathrm{W} \mathrm{m}^{-1} \mathrm{~K}^{-1}\right)$ increases quadratically as a function of increasing snow density (Anderson 1976). There is an additional contribution due to vapor transfer in the snow, which is especially important at low snow densities and high altitudes and is expressed following Sun et al. (1999).

The snow cover is discerned from the soil-vegetation layer in ISBA-ES and CROCUS so that the soil-snow heat flux is explicitly modeled. It is written with the aid of Eq. (10) as

$$
J_{s N}=2\left(D_{s N} \Lambda_{s N}+\Delta z_{1} \lambda_{s}\right)\left[\left(T_{s N}-T_{s}\right) /\left(D_{s N}+\Delta z_{1}\right)^{2}\right] .
$$

The soil thermal conductivity $\lambda_{s}$ is estimated following Etchevers (2000) using the relationships for thermal conductivity from Noilhan and Planton (1989). The upper-layer soil thickness $\Delta z_{1}$ is several centimeters thick.

The incoming shortwave radiation $\left(\mathrm{W} \mathrm{m}^{-2}\right)$ is represented by $R_{g}$, and $\nu_{s}$ is the shortwave radiation extinction coefficient (Bohren and Barkstrom 1974). The snow grain size is needed for this calculation and is parameterized following Anderson (1976). The snow surface albedo is modeled using time constants after Douville et al. (1995a) as

$$
\begin{aligned}
\alpha_{n}^{n}= & \left(P_{n} \Delta t / W_{\mathrm{crn}}\right)\left(\alpha_{\max }-\alpha_{\min }\right) \\
& +\left(1-\omega_{\alpha}\right)\left[\alpha_{n}^{n-1}-\left(\tau_{a} \Delta t / \tau\right)\right] \\
& +\omega_{a}\left[\left(\alpha_{n}^{n-1}-\alpha_{\min }\right) \exp \left(-\tau_{f} \Delta t / \tau\right)+\alpha_{\min }\right] \\
& \quad\left(\alpha_{\min } \leq \alpha_{n} \leq \alpha_{\max }\right)
\end{aligned}
$$

where $\tau_{a}=0.008(\mathrm{~s}), \alpha_{\max }=0.85$, and $\alpha_{\min }=0.50$. A linear decrease rate is used for dry snow (Baker et al. 1990), and an exponential decrease rate is used to model the wet metamorphism (Verseghy 1991). The weight $\omega_{\alpha}$ is defined in ISBA-ES as the degree of saturation $\left(W_{l 1}\right.$ l $\left.W_{l 1 \max }\right)$ when snow is melting, otherwise it is zero. The snow albedo increases at a rate proportional to the snowfall, where the normalization parameter $W_{\text {crn }}$ is given a value of $10 \mathrm{~kg} \mathrm{~m}^{-2}$ (Douville et al. 1995a).

The net heat flux at the atmosphere-snow interface is expressed as

$$
\begin{aligned}
G_{s 0}= & \left(1-\alpha_{n}\right) R_{g}+\epsilon_{n}\left(R_{\mathrm{at}}-\sigma T_{s 1}^{4}\right)-H_{n}-\mathrm{LE}_{n} \\
& +p_{n} P_{l} c_{w}\left[\max \left(T_{a}, T_{f}\right)-T_{f}\right],
\end{aligned}
$$

where $R_{\text {at }}$ is the downwelling atmospheric longwave radiation, the snow emissivity $\epsilon_{n}$ is assumed to be 1 (for all three snow models), and $\sigma$ represents the StefanBoltzmann constant $\left(\mathrm{LE}_{n}\right.$ is defined in section $\left.3 \mathrm{e}\right)$. The last term on the right-hand side of Eq. (14) is a precipitation advection term, where $c_{w}$ represents the specific heat of water.

The heat balance equation for CROCUS is essentially the same as for ISBA-ES. It can be obtained by eliminating $H_{s}$ between Eqs. (7) and (8), and the liquid water content is treated as an explicit prognostic variable. The model uses the same expression for $G_{s 0}$ as ISBA-ES, although the shortwave (solar) radiative and turbulent fluxes are parameterized differently. The incoming solar radiation is split into three different spectral bands, each with a corresponding expression for $\nu_{s}$ and $\alpha_{n}$. Turbulent transfer is discussed in the next section. In terms of heat conduction, CROCUS uses the thermal conductivity model by Yen (1981), except that a correction is used to prevent anomalously low values for small snow densities.

The single ISBA-FR surface temperature $T_{s}$ characterizes the temperature of a composite layer consisting of vegetation, soil, and snow:

$$
\begin{aligned}
\frac{1}{C_{T}} \frac{\partial T_{s}}{\partial t}= & R_{g}\left(1-\alpha_{t}\right)+\epsilon_{t}\left(R_{\mathrm{at}}-\sigma T_{s}^{4}\right)-H_{n}-\mathrm{LE}_{n} \\
& -F_{n}+F_{\mathrm{sw}}-\frac{2 \pi}{\tau C_{T}}\left(T_{s}-T_{2}\right),
\end{aligned}
$$

where $\alpha_{t}$ and $\epsilon_{t}$ represent total (FSCA-weighted snow and nonsnow covered) gridbox average albedo and emissivity, respectively. Expressions for FSCA (used in two-dimensional or gridded model applications) are the same for all three snow schemes and can be found in Douville et al. (1995a). The energy associated with soil 
water phase changes is represented by $F_{\mathrm{sw}}$ (Boone et al. 2000; Giard and Bazile 2000). ISBA-FR uses the same expression for snow albedo as ISBA-ES does [Eq. (13)], except that $\omega_{\alpha}=1$ when the snow is melting. There is no within-snow transmission of $R_{g}$ in ISBA-FR. The thermal inertia $C_{T}$, albedo, and emissivity approach the values for snow in the limit as the FSCA nears unity. The energy available for snowmelt is defined as

$$
F_{n}=p_{n}\left\langle\left\{\left[\operatorname{veg} T_{s}+(1-\operatorname{veg}) T_{2}\right]-T_{f}\right\} /\left(\Delta t L_{f} C_{n}\right)\right\rangle,
$$

where $C_{n}$ is the snow thermal inertia, which is a function of thermal conductivity as in the model of Yen (1981). The vegetation cover fraction is represented by veg. The braced term represents the total potential energy available for snowmelt, and any residual energy is used to heat the adjacent soil (Douville et al. 1995a). Note that when veg $=1$ and $p_{n}=1$, the definition of the energy available for melt in ISBA-FR in the surface snow layer is analagous to that in ISBA-ES and CROCUS; however, the soil-snow heat flux is zero.

The ISBA-ES soil-vegetation surface temperature equation at the point scale (i.e., for $p_{n}=1$ ) is written using a similar expression to that used by CROCUS (Etchevers 2000) as

$$
\frac{1}{C_{T}} \frac{\partial T_{s}}{\partial t}=J_{s N}+Q_{s N}+c_{w} R_{l N}\left(T_{f}-T_{s}\right)+F_{\mathrm{sw}}-G_{g}
$$

where the surface soil-vegetation temperature is represented by $T_{s}$. Note that this definition of $T_{s}$ is different from that used by ISBA-FR [Eq. (15)], which includes the upper layer of the snowpack and therefore includes the snow thermal properties in the definition of $C_{T}$ (as opposed to CROCUS and ISBA-ES) along with the thermal properties of the soil and vegetation. The term involving the snow runoff $R_{I N}$ in Eq. (17) represents an advective term. The ISBA-ES subsurface or ground heat conduction flux $G_{g}$ is the same form as the last term on the right-hand side of Eq. (15). This term is expressed as a heat diffusion term in CROCUS [analagous to the heat flux in Eq. (10), except using the soil thermal conductivity and layer thicknesses]. This simple snow-surface coupling was found to produce reasonable subsurface soil temperatures, soil and snow heat fluxes, infiltration, and runoff for CROCUS for an alpine site (Etchevers 2000) and for a cold continental climate (Schlosser et al. 2000).

\section{e. Surface turbulent fluxes}

The latent heat flux from the snow includes contributions from evaporation of liquid water in the surface snow layer and sublimation, and it is defined as

$$
\begin{gathered}
\mathrm{LE}_{n}=\left[\left(1-W_{l 1} / W_{s 1}\right) L_{f}+L_{v}\right] E_{\mathrm{sn}}, \\
\text { where } \\
E_{\mathrm{sn}}=\rho_{a} C_{H} V_{a}\left[q_{\mathrm{sat}}\left(T_{s 1}\right)-q_{a}\right],
\end{gathered}
$$

and $L_{v}$ denotes the latent heat of vaporization. The frac-

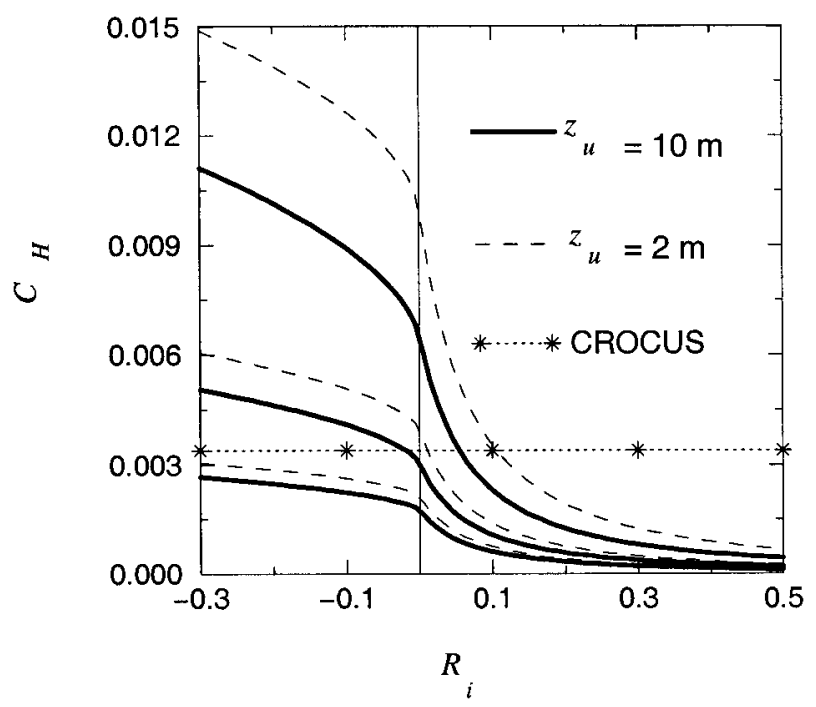

FIG. 1. The ISBA turbulent transfer coefficient $C_{H}$ as a function of the bulk Richardson number $R_{i}$ for two standard values of $z_{u}$ (2 and $10 \mathrm{~m})$ and $z_{a}=2 \mathrm{~m}$. The $C_{H}$ curves for three values of the surface roughness length are shown: $z_{0 t}=10^{-3}, 10^{-2}$, and $10^{-1} \mathrm{~m}\left(C_{H}\right.$ increases for larger $z_{0 t}$ ). The $C_{H}$ value for CROCUS is indicated.

tion of the total mass of the surface layer in the liquid phase is represented by $W_{l 1} / W_{s 1}$, so that evaporation is only possible when $T_{s 1}=T_{f}$ and $W_{l 1}>0$. Atmospheric values for the air density, wind speed, and specific humidity are represented by $\rho_{a}, V_{a}$, and $q_{a}$, respectively. The sensible heat flux is

$$
H_{n}=\rho_{a} C_{p} C_{H} V_{a}\left(T_{s 1}-T_{a}\right),
$$

where $C_{p}$ is the specific heat of air. The turbulent exchange coefficient $C_{H}$ relationship is the same as that used in ISBA-FR (Noilhan and Mahfouf 1996), which is based on the formulation by Louis (1979):

$$
C_{H}=\left[\frac{k^{2}}{\ln \left(z_{u} / z_{0 t}\right) \ln \left(z_{a} / z_{0 t}\right)}\right] f\left(R_{i}\right),
$$

where $z_{u}$ and $z_{a}$ are the heights of the wind and air temperature measurements, respectively, and the von Kármán constant is denoted by $k$. The transfer coefficient $C_{H}$ decreases as a function of increasing stability or $R_{i}$. The gridbox effective surface roughness length $z_{0 t}$ takes into account the effects of both snow and vegetation. The $C_{H}$ coefficient is shown as a function of $R_{i}$ in Fig. 1 for two standard values of $z_{u}(2$ and $10 \mathrm{~m}), z_{a}$ $=2 \mathrm{~m}$, and for $z_{0 t}=10^{-3}, 10^{-2}$, and $10^{-1} \mathrm{~m}$.

The bulk Richardson formulation generally underpredicts turbulent transfer for very stable conditions and small roughness lengths assumed to be typical of snowcovered surfaces (e.g., Hardy et al. 1997; Krinner et al. 1997; Derbyshire 1999; Jordan et al. 1999). ISBA-ES and ISBA-FR use an effective roughness length, which implicitly represents the effects of upstream roughness elements on the snow atmospheric surface layer. CROCUS uses the same basic expressions for $H_{n}$ and LE; 
however, it treats $C_{H}$ as a site-specific calibration parameter.

\section{f. Snow liquid water}

The liquid water content of the snow is modeled as a series of bucket-type reservoirs. Local changes during a model time step arise from snowmelt, water freezing, evaporation, and liquid flow so that

$$
\partial W_{l i} / \partial t=R_{l i-1}-R_{l i}+F_{s i} / L_{f}-\delta_{E}\left(W_{l 1} / W_{s 1}\right) E_{\mathrm{sn}},
$$

where $R_{l}$ represents the water flow between layers $(\mathrm{kg}$ $\mathrm{m}^{-2} \mathrm{~s}^{-1}$ ), and the flux at the snow surface is $R_{l 0}=p_{n}$ $P_{l}$. The term $\delta_{E}$ is unity for the uppermost layer and zero for the other two. Each snow layer has a maximum liquid water holding capacity, which is expressed after Anderson (1976) as

$$
W_{l i \max }=W_{s i}\left[r_{W \min }+\left(r_{W \max }-r_{W \min }\right) \max \left(0, \rho_{r}-\rho_{s i}\right) / \rho_{r}\right] \text {, }
$$

where the constants $r_{W \max }=0.10, r_{W \min }=0.03$, and $\rho_{r}$ $=200 \mathrm{~kg} \mathrm{~m}^{-3}$. A liquid water flux is generated $\left(R_{l}>\right.$ 0 ) when the liquid water content exceeds this threshold. The snow-layer thickness is compacted at a rate proportional to the amount of snowmelt retained in the snow layer (Lynch-Stieglitz 1994), leading to densification. Any meltwater in excess of the layer holding capacity leaves the snow layer and is modeled as a decrease in thickness resulting in a loss of mass from this layer. Water entering a layer is retained (up to the maximum holding capacity and possibly frozen), thereby increasing the layer-average density and mass. Water leaving the lowest snow layer $\left(R_{I N}\right)$ is available for partitioning into soil water infiltration and surface runoff by the SVAT scheme.

CROCUS also uses a series of reservoirs for which the maximum liquid water holding capacity is prescribed to be 5\% of the total pore volume (Pahaut 1976). In terms of the ratio of the mass of liquid water to the total snow mass, CROCUS can retain more liquid water than ISBA-ES can for a layer with an equivalent thickness up to densities of approximately $620 \mathrm{~kg} \mathrm{~m}^{-3}$.

\section{Simulations}

\section{a. Observational site and model setup}

Data from a micrometeorological site located within the Rhone River basin in the French Alps is used to validate ISBA-ES and to intercompare it with results from ISBA-FR and CROCUS. The Col de Porte (CdP) snow research site is operated by the Center for Snow Studies (CEN: Centre d'Etude de la Neige) in Grenoble, France. The site is located at $45^{\circ} \mathrm{N}, 6^{\circ} \mathrm{E}$, with an altitude of $1320 \mathrm{~m}$ above mean sea level. Snow usually covers the surface between November and the beginning of May. Air temperatures well above the freezing point occur intermittently throughout the winter, so that rain and snowmelt episodes are common. Data from this site have been used to evaluate SVAT snow schemes in addition to the models in the current study (e.g., Loth and Graf 1998a; Sun et al. 1999).

All of the atmospheric forcing variables which are necessary to drive the three schemes in offline mode were measured hourly at the site $\left[T_{a}, U_{a}, q_{a}, R_{g}, R_{\mathrm{at}}\right.$, $P_{n}, P_{l}$, pressure, and cloud cover (for CROCUS)]. Temperature and humidity were measured at $z_{a}=2 \mathrm{~m}$, and the wind speed was obtained at $z_{u}=2.5 \mathrm{~m}$. The precipitation type was determined using a combination of heated and unheated rain gauges, and by a third instrument that uses dissolution in alcohol (Brun et al. 1992). The snow depth measurements were taken hourly using an ultrasonic sensor. In addition, weekly snow pit measurements are used to provide SWE, density, and depth. The ultrasonic depth measurements are generally lower than those obtained from the snow pits (approximately $20 \mathrm{~m}$ away), most likely because of increased melting near the depth sensor; however, the measurements are well correlated. The snow-surface temperature was measured from 1993 to 1995, and the albedo was observed from 1994 to 1995. The observed runoff used in this study was measured hourly at CdP in 1994 and 1995 using two $5-\mathrm{m}^{2}$ lysimeters.

The simulation period for the three models is from 1 August 1993 to 31 July 1995. Monthly averages of certain forcing variables are shown in Fig. 2. The two years had contrasting snow seasons: a very warm March significantly reduced the snowpack in 1993/94, which was followed by a relatively cool and snowy April. The 1994/95 snow season was more representative of average conditions: the bulk of the snow fell from January through March and most of the snowpack melted in April and May. Note that the monthly average daily air temperature exceeded the freezing point in all but one month over the 2-yr period.

The CROCUS scheme uses a constant $C_{H}$ value of 0.0034 for this site. This value was obtained through model calibration: the error in predicted surface temperature was minimized using the hourly observed values measured at CdP (Martin and Lejeune 1998). ISBAFR uses an effective surface roughness length $z_{0 t}$ of 0.10 $\mathrm{m}$ for this site, which is the same value used by ISBAFR in Essery et al. (1999) for CdP. This value is significantly larger than those typically used by ISBA-FR for a completely snow-covered homogeneous flat snow surfaces $\left(2.4 \times 10^{-4} \mathrm{~m}\right)$, but, as discussed in Martin and Lejeune (1998), there is a strong influence exerted on the local turbulence during stable conditions by the surrounding mountains. In addition, the southern side of the site is flanked by relatively tall pine trees. ISBAES uses the same effective surface roughness length as ISBA-FR in the current study.

\section{b. Snow depth, density, and SWE}

The snow cover simulations of depth, SWE, and average snowpack density by the three schemes are shown 

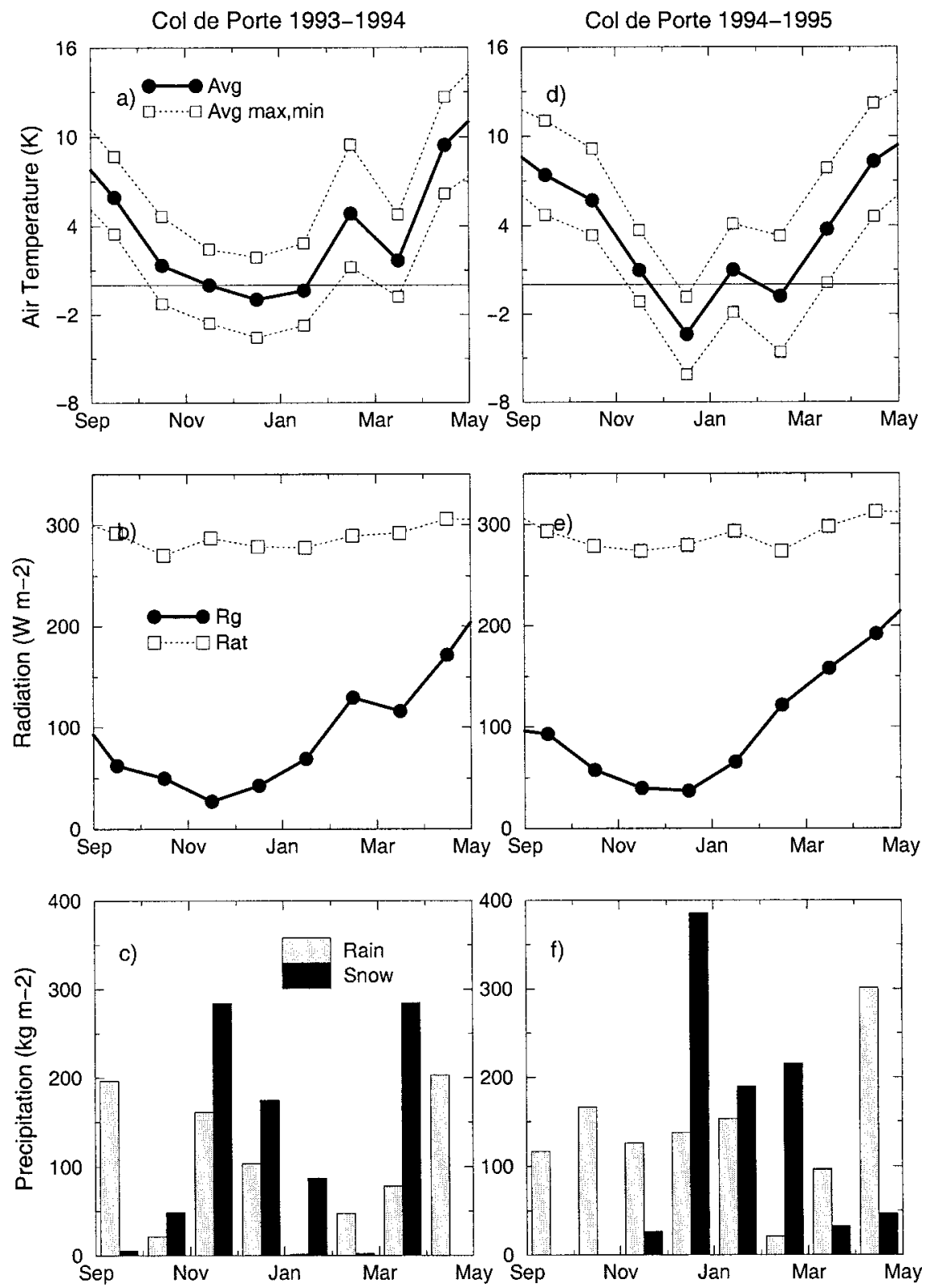

FIG. 2. The atmospheric forcing at Col de Porte for 1993-95 for the months with observed snow cover. (a), (d) Monthly average air temperature $T_{a}$ and monthly average daily max and min temperatures. (b), (e) Atmospheric longwave $R_{\text {at }}$ and incoming solar $R_{g}$ radiation fluxes. (c), (f) Monthly solid $P_{n}$ and liquid $P_{l}$ precipitation totals. The labels denote the end of the month.

in Fig. 3. Here, US is used to indicate snow pit observations by the ultrasonic sensor (opaque squares), and $\mathrm{SP}$ is used to represent snow pit observations (opaque circles). The SWE (Fig. 3b) was overpredicted by ISBAES and ISBA-FR for the winter of $1993 / 94$, but by a larger margin for ISBA-ES. CROCUS simulated it well from early to midwinter and slightly underestimated it in spring.

The primary differences among the three models in simulated SWE evolved early in the winter. A warm spell in mid- to late December resulted in a loss of snow mass from the CROCUS SWE, whereas both ISBA schemes simulated considerably less ablation. The primary source for melting was heat transfer from the atmosphere to the snowpack. The average turbulent transfer in CROCUS was much larger than that for ISBA (FR or ES) at this time (ISBA-FR and ES $C_{H}$ values were, on average, an order of magnitude lower). A second significant melting period occurred in early January. ISBA-FR lost the most mass of all three schemes, and ISBA-ES lost very little. The reason for this is that both the ISBA-ES and ISBA-FR snow covers were very cold 

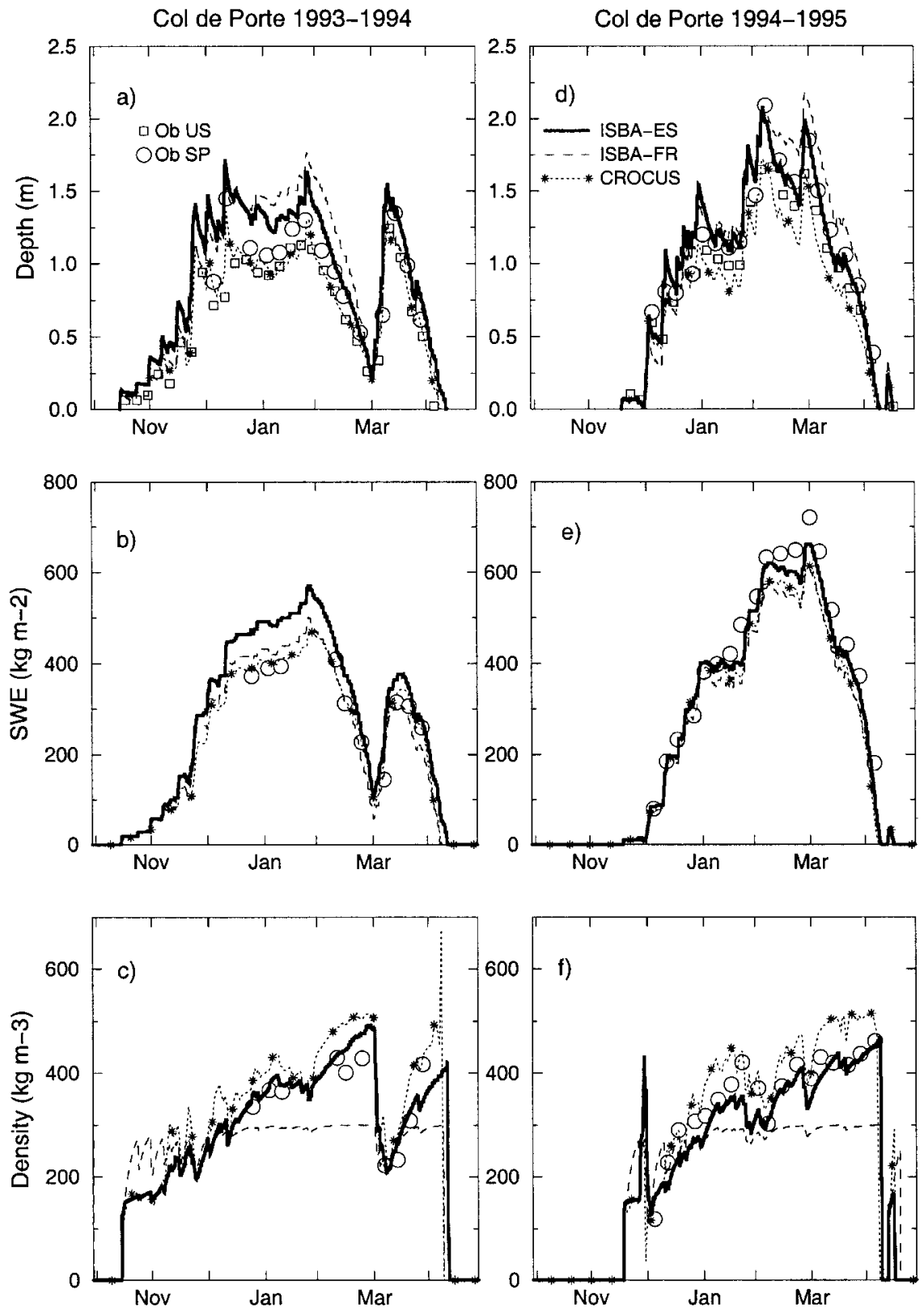

FIG. 3. Simulation results for ISBA-FR, ISBA-ES, and CROCUS for two winter seasons at Col de Porte: (a), (d) total snow depth, along with the snow pit (SP: opaque circles) and snow sensor (US: opaque squares) observations; (b), (e) SWE; (c), (f) Snow density.

leading up to this period, and ISBA-ES refroze a large amount of the snowmelt in the lower two layers of the snowpack. ISBA-FR does not model ripening, so snowmelt immediately left the snowpack. The CROCUS snowpack was warmer because of both earlier melting/ refreezing and more significant atmospheric heat transfer to the snowpack leading up to this period, and much of the snowmelt was lost (as runoff). After this period, the rate of change of SWE by all three models was similar. In spite of the differences in modeled midwinter SWE, the ISBA-FR and CROCUS schemes predicted final ablation to within 2 days of the US observations, whereas the snow completely melted 4 days later in ISBA-ES.

The snowpack average density (1993/94) is shown in Fig. 3c. The ISBA-FR scheme compacted the snow faster than the other two schemes in the absence of snowmelt or precipitation, but the maximum density was lower than that observed at CdP. ISBA-ES predicted the density reasonably well except for a slight overestimation at the end of March and an underestimation at the end of April. The CROCUS predicted density was 
TABle 2. Statistics for 1994/95 at Col de Porte for four time periods: 1) Dec-Jan, 2) Feb-Mar, 3) Apr-May, and 4) 1-3 (averaged over the entire snow season). Results for the three variables presented in Fig. 3 are shown, SWE $\left(W_{s} ; \mathrm{kg} \mathrm{m}^{-2}\right)$, total depth $\left(D_{s}\right.$; m), and average density $\left(\rho_{s} ; \mathrm{kg} \mathrm{m}^{-3}\right)$, along with the daily average snow surface temperature shown in Fig. 5 ( $\left.\bar{T}_{s} ; \mathrm{K}\right)$. Rmse and bias (in parentheses) are shown.

\begin{tabular}{|c|c|c|c|c|c|}
\hline Model & Period & $W_{s}$ & $D_{s}$ & $\rho_{s}$ & $\bar{T}_{s}$ \\
\hline ISBA-ES & 1 & $24.7(-7.69)$ & $0.13(0.04)$ & $43.5(-24.1)$ & $1.52(-1.09)$ \\
\hline ISBA-FR & 1 & $32.2(-25.0)$ & $0.18(-0.11)$ & $42.5(0.02)$ & $1.85(-1.40)$ \\
\hline CROCUS & 1 & $27.2(-8.68)$ & $0.15(-0.13)$ & $31.0(26.8)$ & $0.99(-0.42)$ \\
\hline ISBA-ES & 2 & $44.4(-34.3)$ & $0.09(0.02)$ & $35.4(-28.9)$ & $2.03(-1.57)$ \\
\hline ISBA-FR & 2 & $81.7(-75.7)$ & $0.18(0.14)$ & $87.1(-81.0)$ & $2.45(-1.85)$ \\
\hline CROCUS & 2 & $72.9(-62.7)$ & $0.31(-0.30)$ & $48.6(44.8)$ & $0.80(-0.49)$ \\
\hline ISBA-ES & 3 & $37.1(-35.1)$ & $0.07(-0.04)$ & $20.7(-14.2)$ & $1.94(-1.67)$ \\
\hline ISBA-FR & 3 & $65.6(-64.0)$ & $0.27(0.23)$ & $137.0(-136.3)$ & $2.88(-2.54)$ \\
\hline CROCUS & 3 & $89.8(-86.2)$ & $0.31(-0.31)$ & $64.6(61.2)$ & $0.79(-0.62)$ \\
\hline ISBA-ES & $1-3$ & $38.8(-28.6)$ & $0.10(0.01)$ & $34.2(-23.7)$ & $1.85(-1.42)$ \\
\hline ISBA-FR & $1-3$ & $69.0(-61.2)$ & $0.21(0.11)$ & $97.0(-78.4)$ & $2.34(-1.82)$ \\
\hline CROCUS & $1-3$ & $71.1(-57.2)$ & $0.28(-0.27)$ & $50.5(45.5)$ & $0.97(-0.45)$ \\
\hline
\end{tabular}

generally larger and is more responsive to melting events, such as those in December and January. This was found to be partly due to the larger liquid holding capacity in CROCUS. ISBA-ES overestimated the snow depth (Fig. 3a) for this case primarily because of the overestimation of SWE. CROCUS underpredicted it relative to the SP observations because of large density values; the opposite was true for ISBA-FR.

The SWE in the 1994/95 winter is shown in Fig. 3e. It was simulated best by ISBA-ES for this case, although it was underestimated in late winter. All three of the schemes simulated similar SWE through December, but a melting period in January resulted in the largest loss of mass in CROCUS and ISBA-FR. As was the case for the 1993/94 winter, ISBA-ES accumulated more SWE than ISBA-FR because of the ripening of the snowpack. Once again, the average wintertime value of $C_{H}$ in ISBA (ES and FR) was significantly lower than that of CROCUS; however, this winter was cooler than 1993/94. This resulted in more freezing of a relatively larger amount of the melt and liquid precipitation by CROCUS. As a result, CROCUS had a larger late-winter value of SWE than did ISBA-FR. The density was simulated very well by ISBA-ES for this case and was generally overestimated by CROCUS. The snow depth (SP) was then simulated well by ISBA-ES, was underestimated by CROCUS, and overestimated by ISBA-FR (because of the maximum snow density limit imposed in the model).

Some simple statistics (owing to the limited number of observations) corresponding to the SWE, snow depth, and density for 1994/95 are presented in Table 2. Three time periods are defined for purposes of analysis, and they represent stages in the snowpack evolution as follows. 1) The early winter period (December-January) was when snow first appeared and rapidly accumulated (Fig. 3e). 2) Warm air temperatures (the average monthly value was above freezing; Fig. 2d) were present in the mid to late-winter period (February). In contrast, it was relatively cold in the latter part of this period (March) and most of the precipitation consisted of snow.
3) The spring period (April-May) was characterized by nearly continuous snowmelt and little snowfall.

Several general features can be gleaned from Table 2 in terms of seasonal snowpack evolution at CdP (which are also consistent with the results from 1993/ 94 shown in Fig. 3): First, the simulated SWE was nearly always larger than that simulated by ISBA-FR for all of the periods, which is a direct result of liquid water retention by the snowpack. Second, even though CROCUS and ISBA-ES both ripen the snowpack, simulated SWE can differ significantly. Third, the snow density was underestimated in late winter by ISBA-FR relative to the other two schemes because of its imposed maximum limit (e.g., period 3).

\section{c. Surface energy balance}

All three snow schemes received the same snowfall, so that differences in rainfall retention and snowmelt were the causes for differing predictions of SWE. To understand these differences better, the surface energy balance components are intercompared and evaluated, using the observations, in the following three subsections.

\section{1) SNOW-SURFACE TEMPERATURE}

The daily averaged snow-surface temperatures for the winters of 1993/94 and 1994/95 are shown in Figs. 4 and 5, respectively. Note that the snow-surface temperature was possibly overestimated (Essery et al. 1999), most likely because of instrumentation being incorporated into the field of view of the radiation sensors. Because the bias has not been quantified, the observations are treated as the ground truth in the following section.

The CROCUS $C_{H}$ coefficient has been calibrated using the observed surface temperatures so that they are simulated very well in comparison with the observations (especially for calm, cold nights); the ISBA schemes both have cold biases, especially early in the snow sea- 

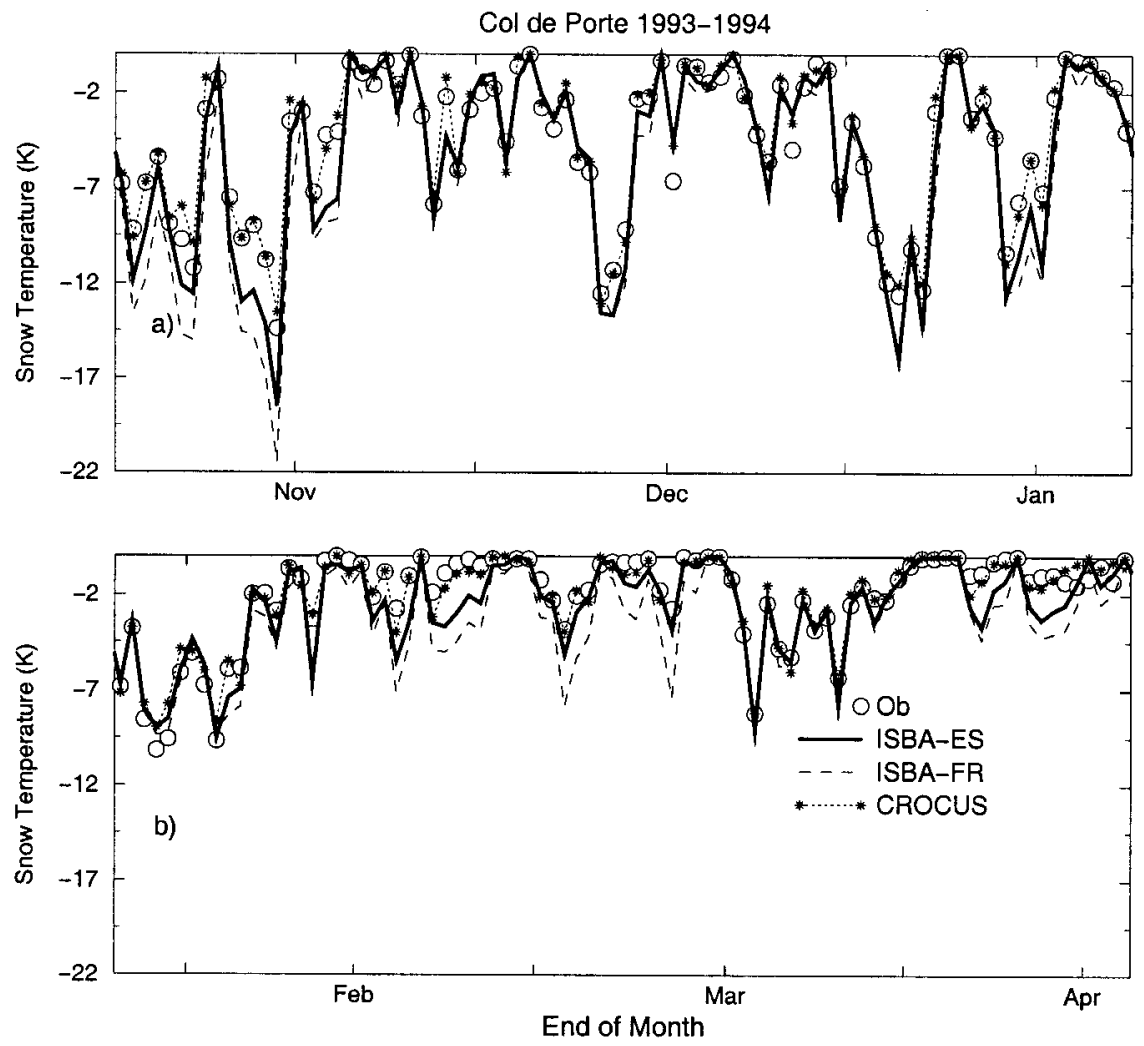

FIG. 4. Daily average surface snow temperatures for ISBA-FR, ISBA-ES, and CROCUS and the observed values (circles) at Col de Porte from 1993 to 1994.
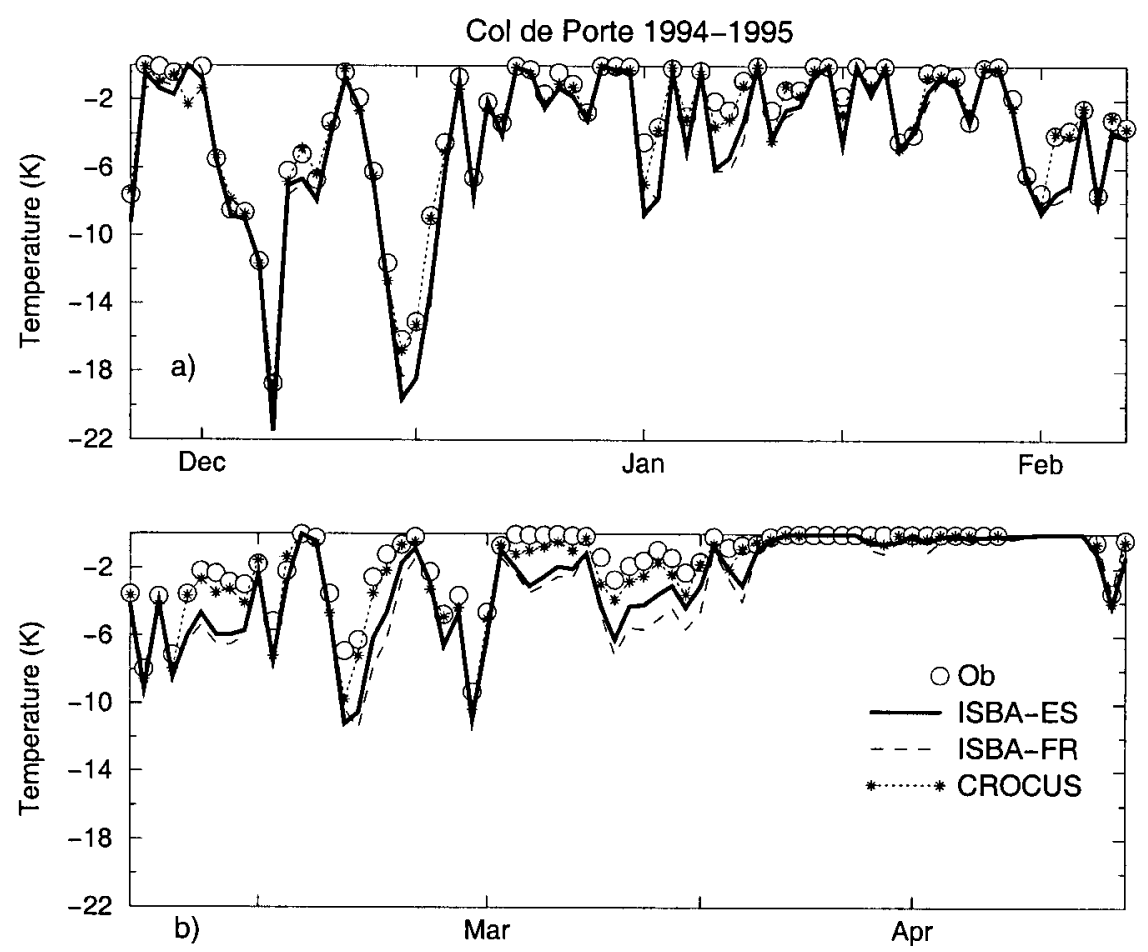

FIG. 5. As in Fig. 4, but for the winter of 1994/95. 
son. The scheme surface temperature rms errors and biases are shown for several time periods for 1994/95 in Table 2. Both ISBA schemes use identical surface flux and turbulent transfer formulations, so differences between these two models were caused by aspects of the snow-scheme physics.

The ISBA-ES and FR surface temperature results generally diverged for two cases. First, the ISBA-ES temperatures can be slightly warmer than those simulated by ISBA-FR for relatively thin, cold (dry) earlyseason snowpacks (e.g., especially November of 1993). The simulated near-surface soil temperature remained near the freezing point in ISBA-ES at CdP for the two years under consideration (in agreement with observations; Etchevers 2000), resulting in a strong thermal gradient between the snow-atmosphere and snow-soil interfaces. Because the snowpack was relatively thin in November of 1993 (less than 0.2 m; see Fig. 3), heat conduction from the underlying soil made a considerable contribution to the ISBA-ES surface energy budget. This can also be seen by the larger ISBA-FR cold temperature biases for the first period in Table 2. In contrast, ISBA-FR only includes the snow properties in the thermal transfer coefficients for $100 \%$ coverage, so that there was no heat conduction from the underlying soil. Note that as the snowpack thickens, however, the two ISBA schemes simulated very similar surface temperatures for both years outside of strong melting events.

Second, ISBA-ES-simulated temperatures tended to be warmer and closer to those observed in the late part of the season. This can be seen in period 3 of Table 2: ISBA-FR cold biases were much colder than both of the other two schemes in this period (although ISBAES still suffered from a cold bias). Snow temperatures in ISBA-FR can drop as soon as melting ceases, whereas ISBA-ES surface temperatures remain at the triple point until all surface-layer liquid water has been frozen or evaporated. This process resulted in the differences in ISBA-ES- and FR-simulated temperatures in March of 1994 (Fig. 4) during a prolonged period of ablation with little snowfall (Figs. 3a,b). Snowmelt caused ISBA-ES to simulate warmer temperatures than ISBA-FR for early April of 1995, although to a lesser extent than for March of 1994, owing to snowfall during this time.

To examine the differences in simulated temperature on a finer timescale, the diurnal cycle for three contrasting 12-day periods during 1993/94 is shown in Fig. 6. The CROCUS scheme simulated the early-season (Fig. 6a) temperature very well as compared with the observations, primarily because of the larger turbulent heat flux into the snowpack. The ISBA schemes' cold bias is clearly evident, with slight differences in terms of nighttime temperatures being related to the soil-snow conduction flux (as discussed above). In the middle of the season for a deep snowpack (Fig. 6b) and generally cold air temperatures, all three schemes simulated the surface temperature in a similar manner (and similar fluxes; see Fig. 8 below). The three schemes tended to overestimate the nighttime minimum temperature when compared with the observations for several days in the middle of the month, but overall the period was satisfactorily simulated. During the strong late-season melting event in March (Fig. 6c), the inclusion of latent heating due to liquid water and ice-phase changes in CROCUS and ISBA-ES resulted in reasonably well simulated daily cycles, but ISBA-FR continued to have a more significant cold bias. Loth and Graf (1998b) and Jin et al. (1999) found the same deficiency in simulating freeze-thaw cycles during snowpack ablation using SVAT snow schemes that did not retain liquid water.

\section{2) SNOw Albedo}

The observed and modeled snow albedo for the winter of 1994/95 are presented in Fig. 7. It should be noted that the observed snow albedo was underestimated (Essery et al. 1999) for the same reason that surface temperature was possibly overestimated (see previous section).

The CROCUS-simulated daily average snow albedo was generally larger than that simulated by both ISBAES and FR, especially during prolonged melting periods, when differences can be on the order of 0.15 or more (e.g., early April and May in Fig. 7). This difference was important during the spring season at $\mathrm{CdP}$ owing to the relatively large solar-radiation forcing. Based on the observations, two generalizations can be made. First, the observed snow albedo attains values that were as high as 0.95 after snowfall events, which was generally larger than those simulated by CROCUS and well above the maximum limit $\left(\alpha_{\max }=0.85\right)$ imposed by ISBA-ES and FR. Second, the snow albedo decreased at a faster rate or by a larger magnitude than that simulated by all of the models. Whether this is related to deficiencies in the model formulations or is due to a lack of explicitly modeling deposition of soot, dirt, or debris should be investigated using nonbiased albedo observations. In summary, ISBA-ES and FR generally have more solar energy available for melting the snowpack than does CROCUS in the spring, which offsets to some degree the larger turbulent transfer of heat by CROCUS at this time.

\section{3) Surface fluXes}

The cumulative surface energy budget components for the three snow models during the 1993/94 and 1994/ 95 winter seasons are shown in Figs. 8 and 9, respectively. The surface fluxes were not observed, and only the fluxes for the time period when all three model surfaces were completely snow covered are shown (i.e., $p_{n}=1$ ). The surface net radiative flux is shown in Fig. 8a and Fig. 9a, and it is defined as

$$
R_{n}=\left(1-\alpha_{n}\right) R_{g}+\epsilon_{n}\left(R_{\mathrm{at}}-\sigma T_{s}^{4}\right),
$$

where only the surface snow temperature (denoted here 

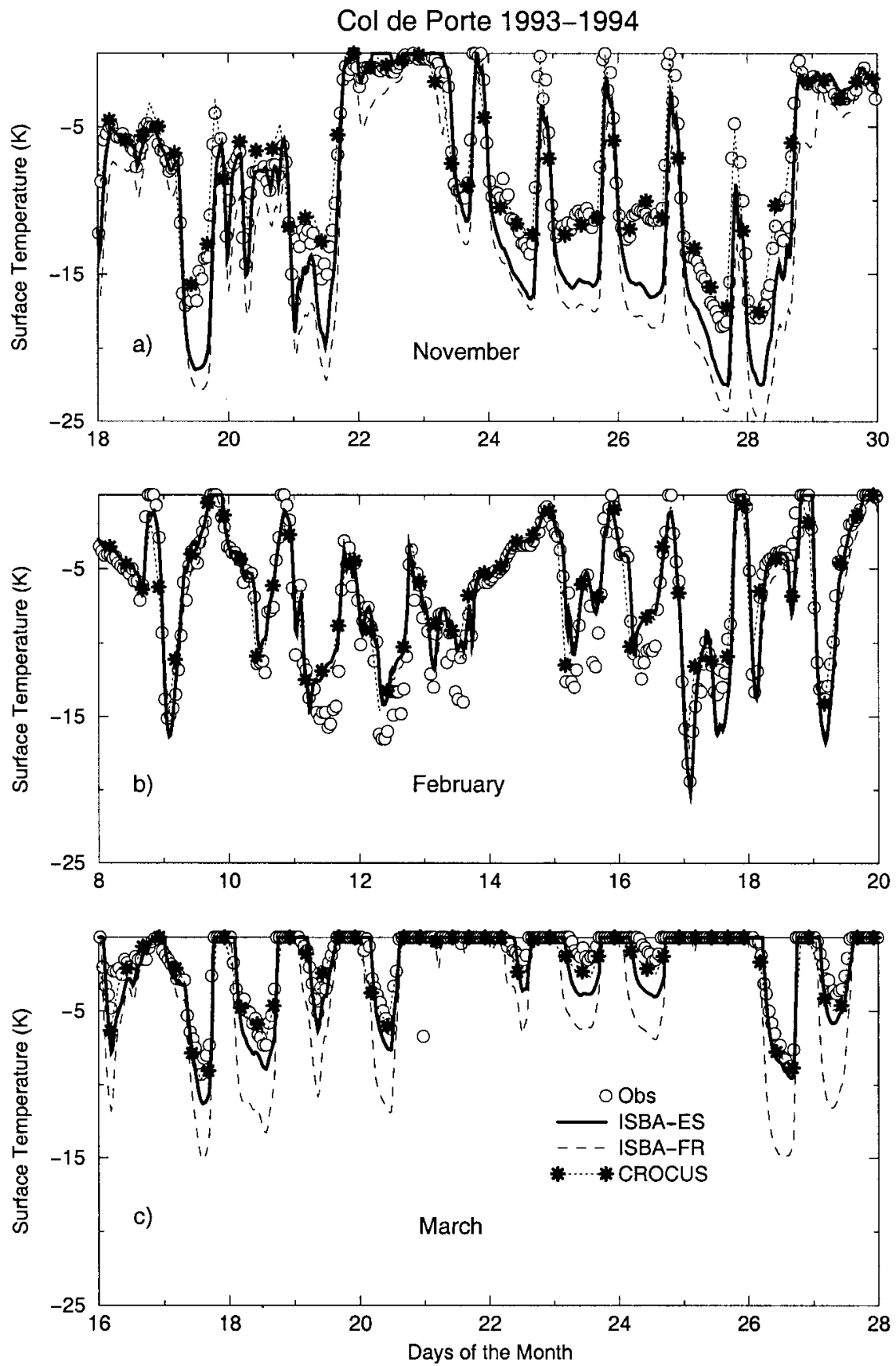

FIG. 6. The model-simulated snow surface temperature diurnal cycle for three 12-day periods during 1993/94. The time series for the three snow schemes are shown, and the observations are represented by circles. The time periods are defined in terms of snowpack evolution: 1) early (Nov), 2) midwinter (Feb), and 3) late winter (Mar).

as $T_{s}$ ) and $\alpha_{n}$ vary among the schemes when the surface is totally snow covered. The cumulative sensible heat flux $H_{n}$, latent heat flux LE, and surface net heat flux $G$ are shown in Figs. 8b-d and Figs. 9b-d, respectively. The cumulative advective precipitation heat flux [see Eq. (14)] was nearly the same for both ISBA-ES and CROCUS, but it was neglected in the calculation of the cumulative net heat flux in Figs. 8 and 9, because it was considerably less than the other three terms.

The turbulent transfer of heat toward the snowpack from the atmosphere $\left(H_{n}+\mathrm{LE}\right)$ was the largest for CROCUS for both winter seasons, which resulted in the warmest snow surface temperatures, especially for relatively calm, clear conditions. This in turn resulted in 
Col de Porte 1994-1995
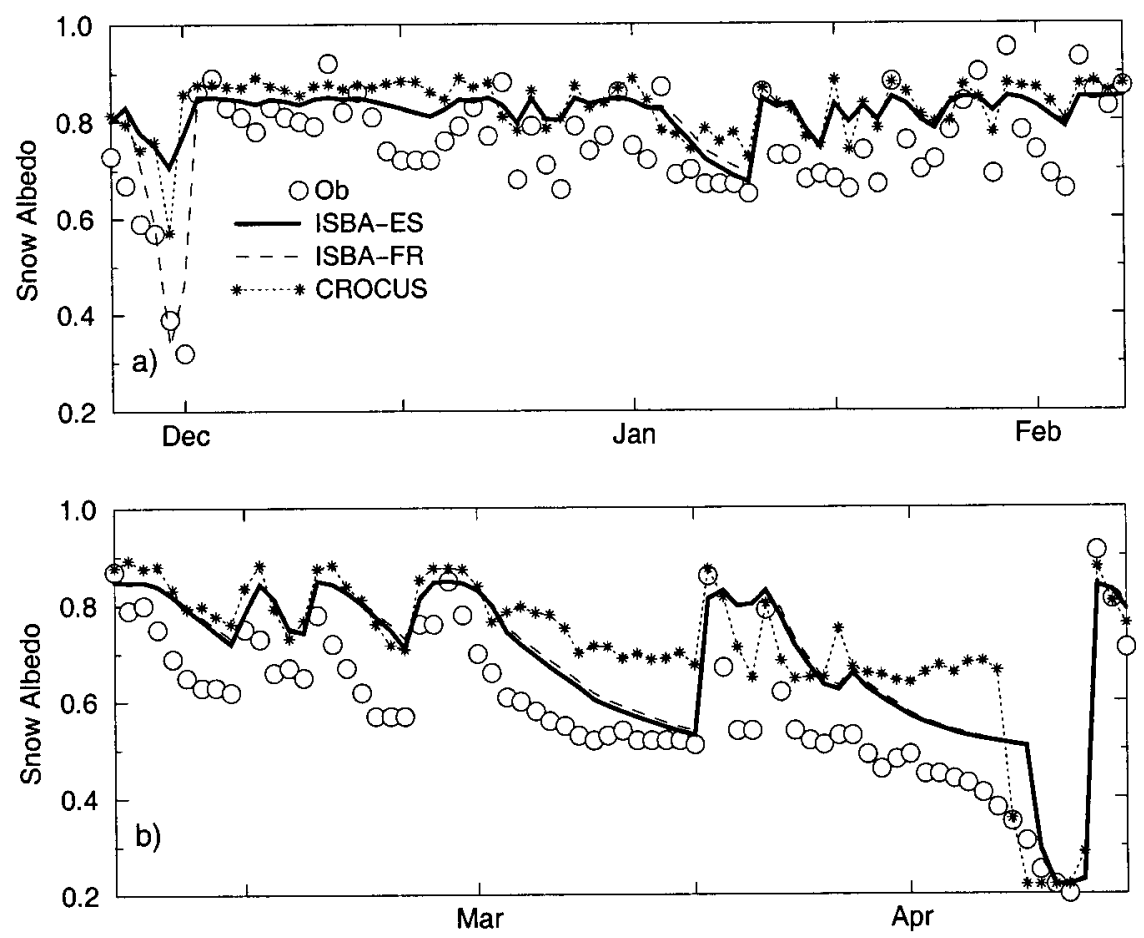

FIG. 7. The daily average snow surface albedo simulated by ISBA-FR, ISBA-ES, and CROCUS for the 1994/95 winter. Observations are represented by circles.

a larger radiative flux of heat away from the surface from the beginning of the snowpack through February of 1994 and March of 1995 for CROCUS. There was a further departure between $R_{n}$ simulated by CROCUS and by the two ISBA schemes during the primary ablation periods in March and the end of April because of the lower snow albedos (increased net solar radiation) for the two ISBA schemes. The cumulative net heat flux for the three schemes over the entire snow season (not shown) was similar; however, the differences in partitioning of available energy into turbulent and radiative fluxes is of importance with respect to coupling with atmospheric models, for which feedbacks could be very different depending on this partitioning.

\section{d. Snowpack runoff}

Whereas the influence of melting on the surface snow temperature and the change in surface characteristics (albedo, aerodynamic roughness) are of more importance for atmospheric modeling, the timing and magnitude of the snowpack runoff are of critical importance for hydrological modeling. Snow runoff is defined in the current study as the liquid water flow at the base of the snowpack, which is generated when liquid water within or intercepted by the snowpack exceeds the holding capacity. Note that the runoff observations and intercomparison presented in this study were for $1 \mathrm{yr}$ at $\mathrm{CdP}$ and were examined to explain first-order model differences: the purpose was not to determine that any one scheme generally simulates runoff better than any other (which is obviously not possible based on $1 \mathrm{yr}$ of data).

The daily accumulated snow runoff from the three snow models and the observations is shown in Fig. 10 for the winter of 1994/95, and the corresponding monthly accumulated runoff is shown in Fig. 11. The three time periods that were defined for purposes of analyzing the snowpack state in 1994/95 can also be used to identify several stages of runoff, as follows. 1) The earlywinter period (December-January) was characterized by intermittent runoff which was caused by precipitation and relatively short melting periods. 2) Considerable runoff occurred in the mid- to late-winter period in the latter part of February (Fig. 10a) because of rainfall and warm air temperatures. In contrast, in March it was relatively cold and snowy, resulting in much less runoff. 3) The spring period (April-May) was characterized by nearly continuous runoff associated with snowmelt and rainfall events. Runoff statistics [rmse, correlation squared, efficiency or Nash coefficient (Nash and Sutcliffe 1970), and the ratio of the modeled over observed runoff] are shown in Table 3 for the three aforementioned time periods and averaged over the entire snow season.

ISBA-FR simulated runoff first (of the three models) during the early-winter period (Fig. 10), and total monthly runoff was largest in December and January 

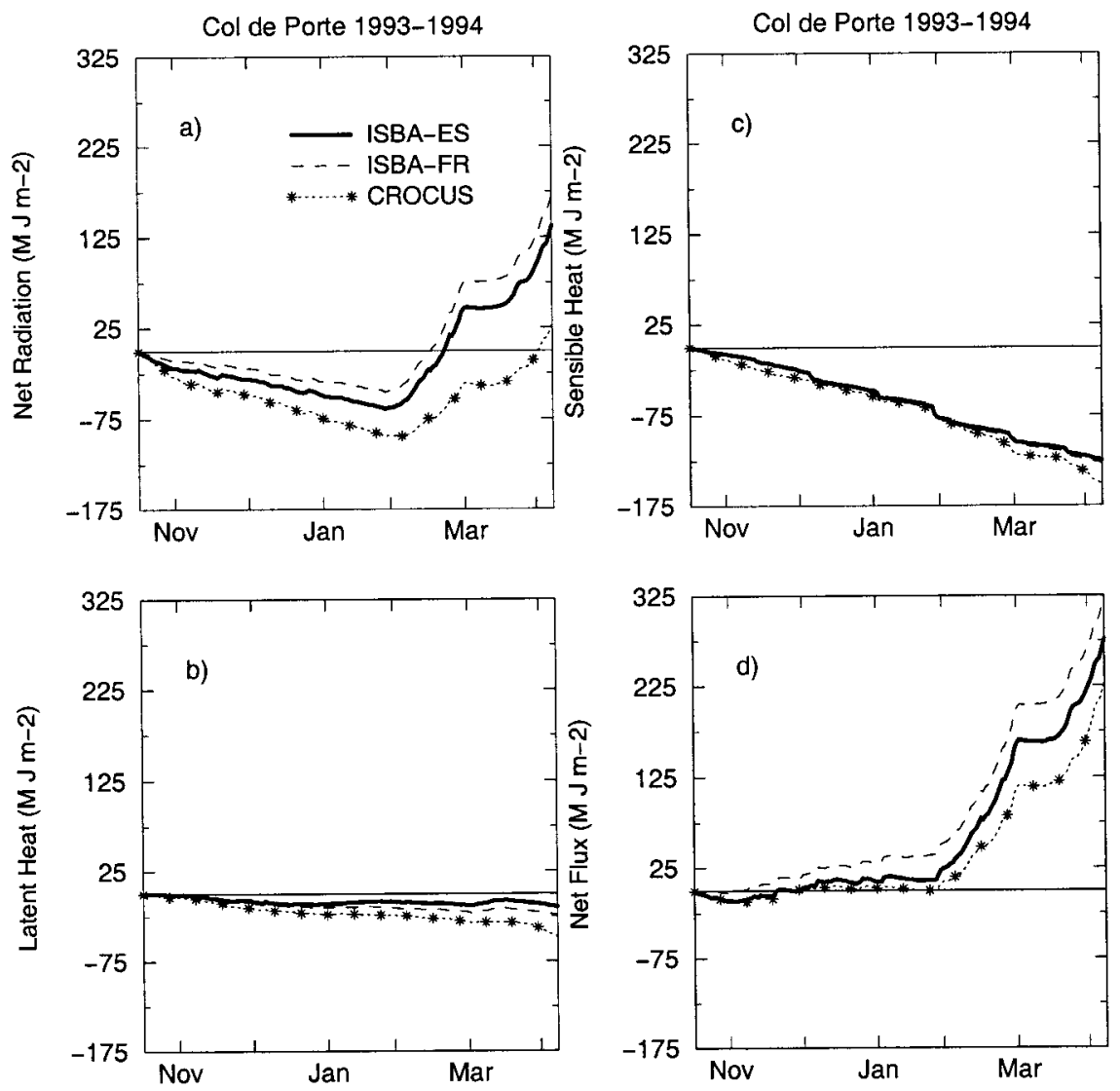

FIG. 8. The (a) cumulative net radiation $R_{n}$, (b) latent heat LE, (c) sensible heat $H_{n}$, and (d) net surface heat $G$ fluxes for ISBA-FR, ISBA-ES, and CROCUS. Results are shown for Col de Porte during the 1993/94 winter.

(Fig. 11). CROCUS simulated the best overall runoff as compared with the observations for this period, although ISBA-ES statistics were similar (Table 3): the total simulated runoff was nearly identical (although slightly overestimated). ISBA-FR simulated 1.32 times more runoff than that observed and the lowest SWE by the end of this period (Fig. 3e). January was very cold, and the solar radiation was weak (Fig. 2), thereby limiting melting: most of the runoff simulated by ISBAFR was from liquid precipitation, owing to the lack of liquid water retention.

In February and March, CROCUS simulated the most monthly runoff of the three models (1.25 times that observed). The modeled snowmelt episodes were the most significant of the three models, mainly because of the larger turbulent heat flux into the snow from the fact that the average air temperatures were above freezing (Fig. 2d). ISBA-FR lost melt as runoff, whereas ISBA-ES incorporated part of it back into the snowpack: the best overall runoff statistics were simulated by ISBA-FR, although the ISBA-ES statistics were similar (Table 3).

During the last 2 months when the snowpack was ablating, CROCUS tended to overestimate the runoff peaks for several days in mid- to late April (Fig. 10). ISBA-FR tended to underestimate it slightly. During this time, the air temperature was above freezing and more heat was transferred from the atmosphere to the snowpack (Fig. 9c) in CROCUS. In addition, the albedo simulated by CROCUS was lower than that in either ISBA scheme (Fig. 7b), so that melting was much more intense in CROCUS. In terms of monthly totals, ISBA-ES and CROCUS simulated similar amounts of maximum runoff in April and more than that simulated by ISBA-FR (Fig. 11). ISBA-ES simulated more in May than CROCUS because the snowpack duration was longer (because of larger mass losses by CROCUS in February and March). As compared with ISBA-FR, ISBA-ES simulated more runoff late in the season when the additional mass (liquid water and refrozen meltwater or rain) was melted. The same general trend was found in ISBA-FR when compared with CROCUS, however CROCUS tended to simulate more midwinter melt at CdP than did both ISBA schemes, so that there was less available for spring melt for this particular case. The best runoff statistics were simulated by ISBA-ES during the final 2-month period (Table 3). 

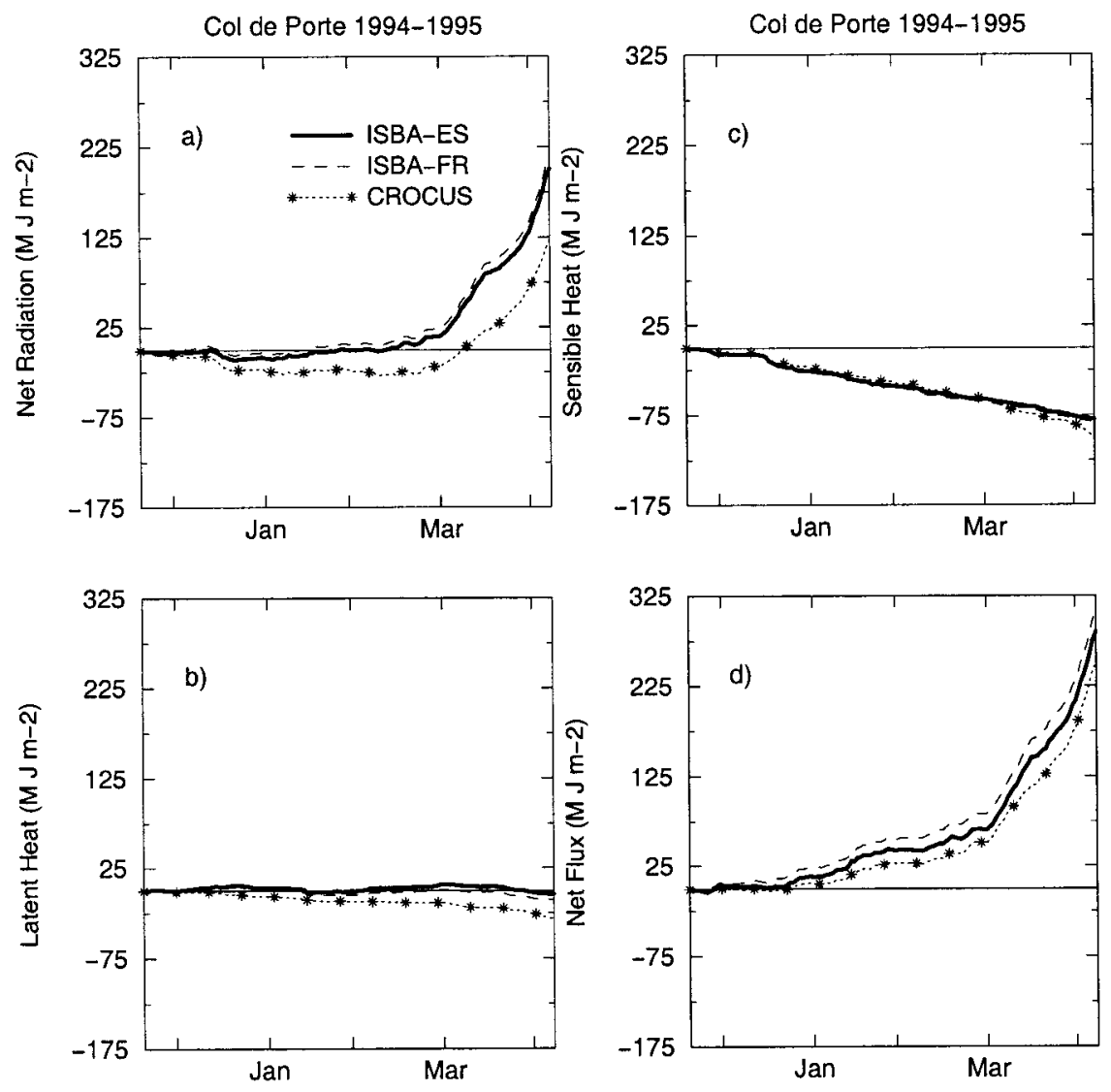

FIG. 9. As in Fig. 8, but for the 1994/95 winter.

\section{Sensitivity tests}

Several sensitivity tests related to some of the parameterization schemes were done using ISBA-ES based on the results of other studies using similar schemes. Statistical results for the entire 1994/95 season at CdP are shown in Table 4. Note that the same general tendencies were obtained for both years at $\mathrm{CdP}$ for the sensitivity tests summarized in this table.

The CROCUS turbulent transfer coefficient value was used to limit the value in ISBA-ES (test 1). Note that the effective surface length was then changed to a typical surface roughness length over snow (consistent with CROCUS). It did result in reducing the nighttime cold bias of the model; however, during springtime the snowmelt was excessive when compared with the control case and CROCUS. This resulted because the ISBA-ES simulated snow albedo is much lower than that of CROCUS during prolonged periods of snowmelt (e.g., Fig. 7). The SWE simulation by ISBA-ES for 1994/95 was greatly underestimated. The 1993/94 midwinter SWE overestimation was reduced (and improved); however, the snowpack ablated too early in the season (degrading the SWE result).

A less stringent turbulence limit was imposed (test 2). The Richardson number maximum in Table 4 cor- responds to a minimum $C_{H}$ of approximately 0.001 (which is still in line with observations; e.g., Jordan 1991). The results were then nearly the same as the control case, except that the cold bias was reduced by approximately $40 \%$. The fact that the model can be very sensitive to the imposed $C_{H}$ (or $R_{i}$ ) limit underscores the need to investigate more thoroughly the turbulent exchange for very stable conditions over snow cover.

The simulation results were sensitive to the maximum liquid water capacity parameter [test 3; as discussed in detail by Loth and Graf (1998b); Essery et al. (1999); Jin et al. (1999); Etchevers (2000)]. The method used in CROCUS was tested in ISBA-ES, and the cold bias was reduced at CdP because of greater refreezing, and the SWE was increased (note the positive bias) and slightly overestimated rather than underestimated (control case), with approximately the same errors. However, SWE was overestimated by a larger amount than in the baseline simulation for 1993/94.

The snow had no liquid holding capacity in test 4 (as in ISBA-FR): SWE was more significantly underestimated and the cold bias was augmented. Tests 3 and 4 illustrate the interplay between the maximum liquid water retention and turbulent transfer parameterizations, especially in the early to midpart of winter: a larger 

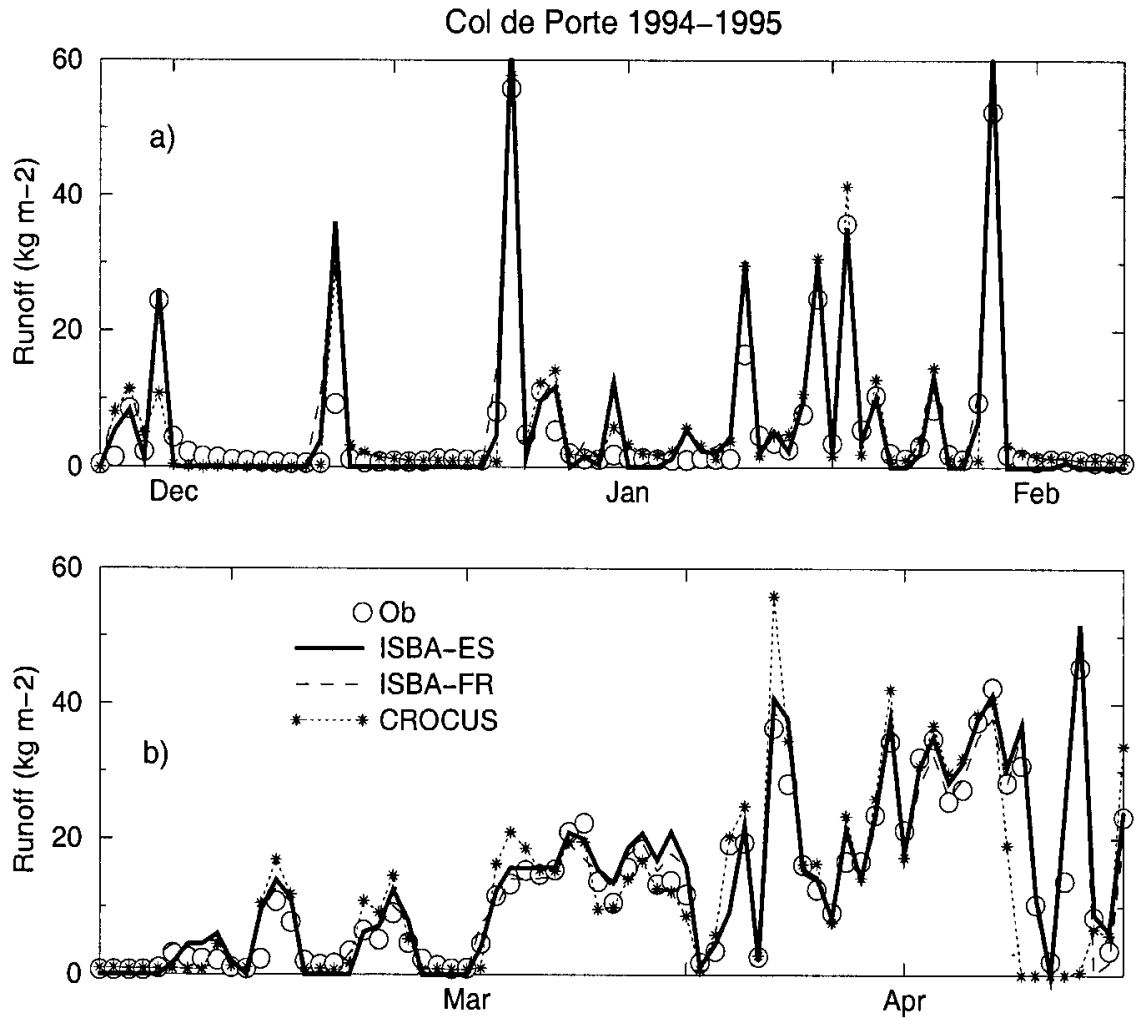

FIG. 10. The daily total snow runoff simulated by ISBA-FR, ISBA-ES, and CROCUS during the 1994/95 winter. The observed runoff totals are represented by opaque circles. Snow runoff is defined as liquid precipitation and snowmelt that is in excess of the snow-cover holding capacity.

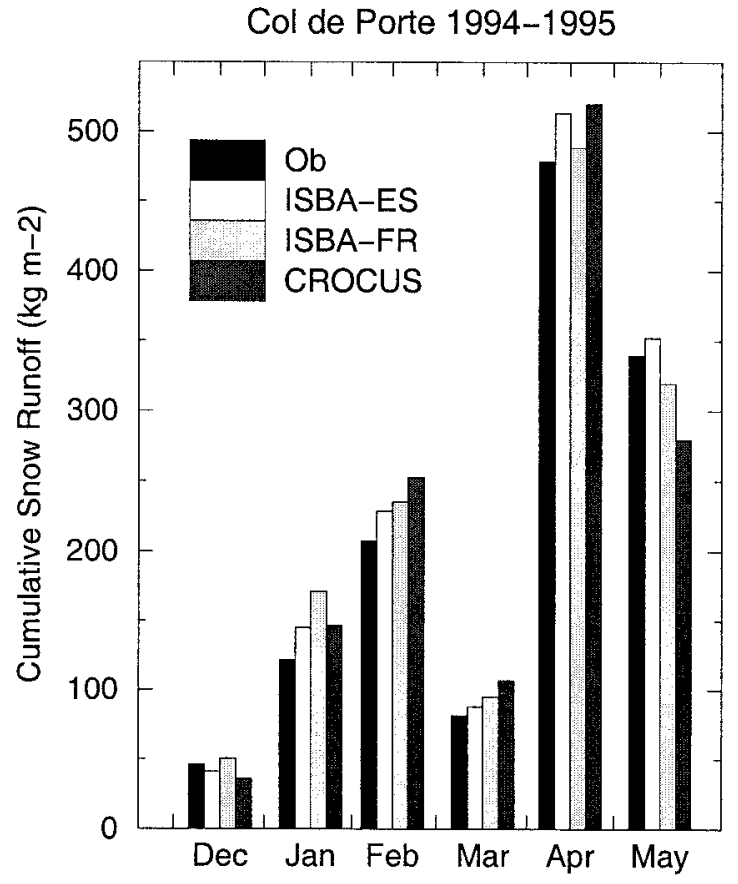

FIG. 11. The monthly total snow runoff for the 1994/95 winter for ISBA-FR, ISBA-ES, CROCUS, and the observed values. liquid holding capacity can, to some degree, offset a cold bias induced by an underestimate of turbulent heat transfer to the snow if there is melting or rainfall.

Consistent with some SVAT schemes (see Schlosser et al. 2000), the albedo was set to a constant value for test 5 . The value is very close to the average albedo during the meltdown phase (March-May). In March of

TABle 3. Total daily runoff statistics for 1994/95 at Col de Porte for four time periods (as in Table 2). The correlation coefficient squared $r 2$, rmse $\left(\mathrm{kg} \mathrm{m}^{-2}\right)$, the efficiency or Nash coefficient (Nash), and the ratio of the modeled $\left(R_{I N}\right)$ to the observed total snow runoff $\left(R_{\text {lob }}\right)$ are shown.

\begin{tabular}{lccccc}
\hline \hline \multicolumn{1}{c}{ Model } & Period & Rmse & $r 2$ & Nash & $R_{L N} / R_{\text {lob }}$ \\
\hline ISBA-ES & 1 & 4.74 & 0.839 & 0.710 & 1.110 \\
ISBA-FR & 1 & 5.12 & 0.815 & 0.661 & 1.320 \\
CROCUS* & 1 & 4.22 & 0.807 & 0.770 & 1.089 \\
ISBA-ES & 2 & 3.06 & 0.934 & 0.874 & 1.097 \\
ISBA-FR* & 2 & 2.73 & 0.946 & 0.900 & 1.145 \\
CROCUS & 2 & 3.50 & 0.933 & 0.835 & 1.247 \\
ISBA-ES* & 3 & 3.25 & 0.929 & 0.910 & 1.058 \\
ISBA-FR & 3 & 3.40 & 0.910 & 0.901 & 0.988 \\
CROCUS & 3 & 7.79 & 0.647 & 0.481 & 0.977 \\
ISBA-ES & $1-3$ & 3.70 & 0.924 & 0.892 & 1.074 \\
ISBA-FR & $1-3$ & 3.79 & 0.907 & 0.886 & 1.067 \\
CROCUS & $1-3$ & 5.35 & 0.819 & 0.772 & 1.053 \\
\hline
\end{tabular}

* Best 3 out of 4 statistical measures as compared with the observations. 
TABLE 4. Statistics for sensitivity tests using ISBA-ES for 1994/95 at Col de Porte averaged over the entire snow season. Results are for $\operatorname{SWE}\left(W_{s} ; \mathrm{kg} \mathrm{m}^{-2}\right)$, total depth $\left(D_{s} ; \mathrm{m}\right)$, and average density $\left(\rho_{s} ; \mathrm{kg} \mathrm{m}^{-3}\right)$, along with the daily average snow surface temperature $\left(\bar{T}_{s} ; \mathrm{K}\right)$. Rmse and bias (in parentheses) are shown.

\begin{tabular}{lrlrl}
\hline \hline \multicolumn{1}{c}{ Test } & $W_{s}$ & \multicolumn{1}{c}{$D_{s}$} & \multicolumn{1}{c}{$\rho_{s}$} & $\bar{T}_{s}$ \\
\hline 0) Control & $38.8(-28.6)$ & $0.10(0.01)$ & $34.2(-23.7)$ & $1.85(-1.42)$ \\
1) $C_{H} \geq 0.003, z_{0 t} \approx 0.001 \mathrm{~m}$ & $110.5(-92.1)$ & $0.21(-0.13)$ & $116.3(-57.9)$ & $0.61(-0.19)$ \\
2) $R_{i} \leq 0.05, z_{0 t} \approx 0.001 \mathrm{~m}$ & $40.4(-31.8)$ & $0.10(0.01)$ & $36.5(-27.0)$ & $1.25(-0.83)$ \\
3) $W_{\text {imax }}$ (CROCUS) & $40.8(23.7)$ & $0.15(0.11)$ & $25.8(-13.5)$ & $1.44(-0.90)$ \\
4) $W_{l \max }=0$ (ISBA-FR) & $84.1(-76.0)$ & $0.12(-0.06)$ & $50.6(-43.4)$ & $2.45(-1.83)$ \\
5) $\alpha_{n}=0.70$ & $101.9(-86.9)$ & $0.18(-0.13)$ & $40.0(-31.6)$ & $1.61(-1.07)$ \\
6) $\Lambda_{s}$ (Yen 1981; CROCUS) & $53.4(-45.9)$ & $0.10(-0.03)$ & $38.6(-29.6)$ & $2.23(-1.63)$ \\
7) $D_{s 1} \leq 0.02, D_{s 2} \leq 0.20 \mathrm{~m}$ & $41.3(-31.3)$ & $0.09(-0.02)$ & $32.7(-21.4)$ & $1.88(-1.36)$ \\
8) $N_{s}=1$ & $199.5(124.6)$ & $0.42(0.31)$ & $36.4(-3.53)$ & $1.99(-0.16)$ \\
9) $N_{s} 2$ & $55.1(-47.4)$ & $0.11(-0.07)$ & $30.1(-19.3)$ & $2.30(-1.69)$ \\
10) $N_{s}=5$ & $38.5(-28.8)$ & $0.10(0.03)$ & $42.2(-30.4)$ & $1.89(-1.35)$ \\
\hline
\end{tabular}

1995, significant snow events resulted in both high observed and simulated (control) average albedo. When the albedo was constant, considerable snowmelt occurred in March owing the relatively large solar radiation. The melting rate in April was reduced in comparison with the control case, but the end result was larger errors in simulated SWE (especially in March and early April). Based on this simple test, the ability to have a dynamic albedo that refreshes during snowfall events and can decrease with age/melting is important in terms of correctly simulating melt rates and SWE on timescales smaller than an entire season, even if the time of final ablation is unchanged using a constant albedo.

Loth and Graf (1998b) found significant simulated snow depth differences depending on whether they used the Anderson (1976) or Yen (1981) methods. The default thermal conductivity was replaced by the method of Yen (1981) using the lower limit imposed by CROCUS (test 6). Because the Yen thermal conductivity tended to be lower, the surface and second-layer temperatures were more decoupled: this tended to increase the cold bias in the model while reducing the SWE (the lower two layers did not cool as readily and therefore there was less freezing of percolated water and more runoff).

Last, tests were done on snow-layer geometry. In test 7 , the maximum surface and second-layer thicknesses were reduced by a factor of 2.5 (to 0.02 and $0.20 \mathrm{~m}$, respectively) as recommended by Sun et al. (1999). This reduction had a small impact on the diurnal surfacetemperature cycle during ablation due to the relatively lower amount of surface-layer liquid water available for refreezing [as discussed in Jin et al. (1999)], but overall there was little change in the error statistics averaged over the entire melting season.

The ISBA-ES three-layer scheme was then replaced by a bulk single-layer configuration (test 8 ) as in Sun et al. (1999). Consistent with their study at CdP, SWE was overestimated and there was a large degradation in results, primarily due to damped amplitude of the diurnal cycle (and underestimation of snowmelt) for large snow depths. Snow was present for several weeks past the observed ablation.

The simulations were also redone using a two-layer configuration (test 9) in which the uppermost layer was limited to a thickness of $0.05 \mathrm{~m}$ (as in the control case). The simulation of SWE was slightly worsened, and the surface-temperature cold bias was increased. The use of a second/intermediate layer seems to be necessary to resolve intermediate timescales (other than daily and annual) better. Jin et al. (1999) also noted the need to have a minimum of a three-layer structure for a mountainous site because of three distinct thermal regimes they observed: a thin rapid-response surface layer, which could be very cold; a deep, nearly constantly saturated layer; and an intermediate layer, which could be wet or dry depending on recent atmospheric conditions. This same basic profile is often observed at $\mathrm{CdP}$.

The final test (10) consisted in increasing the vertical resolution by adding two additional layers. The modeled SWE and temperature bias were nearly unchanged as compared with the control simulation for this case, even though the observed thermal gradient through the entire snowpack depth can be large (over $15 \mathrm{~K}$ at times at CdP for 1994/95). The number of layers was further increased to 10 (not shown), and the statistical differences were nearly negligible between this and test 10 . These basic tests further enforce the recommendation by other modelers for using three layers. Note that the results of the sensitivity tests presented in this study were obtained for the CdP site for two winter seasons, so that these results are not conclusive, and they will be repeated in ongoing studies for other sites (climates).

\section{Conclusions}

A new three-layer explicit snow-scheme option in ISBA (called ISBA-ES) has been evaluated using prescribed atmospheric forcing in stand-alone mode at the local scale for an alpine site. In addition, the scheme was compared with both a more simple model and a more complex snow scheme. The results were compared 
with available observations, and the most significant causes for errors and interscheme differences were discussed.

The simulated SWE is consistently larger for ISBAES when compared with the more simple ISBA-FR scheme, primarily because of the inclusion of liquid water retention in ISBA-ES. This retention also tended to increase springtime snowmelt runoff at the expense of early winter runoff when compared with ISBA-FR. In addition, snow-surface temperatures were better simulated by ISBA-ES in comparison with ISBA-FR during extended snowmelt periods because of latent heating resulting from freezing of snow liquid water and when the snowpack was relatively thin (owing to the explicit snow-soil heat flux in ISBA-ES), although both ISBA schemes had cold biases early in the season.

Differences in modeled SWE between ISBA-ES and the more complex CROCUS scheme were related to contrasting surface flux parameterizations more than to internal snow physics. The largest differences were found for early to midwinter, when CROCUS lost more snow mass, primarily owing to the larger turbulent transfer. The related overestimation of the cold content of the snow by ISBA-ES resulted in greater retention (refreezing) of snowmelt. Indeed, Schlosser et al. (2000) noted the tendency of SVAT schemes (such as ISBA) to have difficulties modeling early to midwinter melt episodes. This could be related to their turbulent transfer formulations, based on the results in this study.

It is evident that turbulent transfer in the two ISBA schemes is underestimated at night, based on observed snow surface temperatures at CdP. An effective surface roughness length was used to account for the effect of mountainous terrain and a neighboring pine forest on the local turbulence. The use of an effective surface roughness length in ISBA-ES does result in increased turbulent transfer relative to that for a flat homogeneous snow surface. However, a large roughness length tends to decrease the temperature contrast between the atmosphere and the snow surface so that turbulent transfer can still be underestimated (Martin and Lejeune 1998). Indeed, the large bulk Richardson numbers calculated by ISBA-ES resulted in extremely weak transfer during very stable conditions and in underestimates of surface temperature despite use of an effective roughness length.

In addition, note that, at higher-altitude stations or sites where the air temperature is colder (not shown), the larger value of $C_{H}$ used by CROCUS does not induce much midseason melt. In fact, it can enhance condensation somewhat relative to the ISBA schemes, thereby augmenting SWE [as was the case for a cold continental site; Schlosser et al. (1999)]. The combined result of the generally larger liquid holding capacity and increased condensation is that CROCUS generally simulates the largest SWE of the three models at highaltitude sites (Boone 2000). ISBA-ES generally simu- lates a similar but slightly lower amount; ISBA-FR is generally much lower.

Despite the lack of explicit consideration of detailed stratigraphy or snow metamorphism, the mean snowpack density was simulated well as compared with the observations, and model results compared favorably with the much more complicated CROCUS multilayer snow scheme. An accurate simulation of this variable is important, because many of the physical parameterization schemes in the model are functions of snow density. In addition, there are many sites that record snow depth [in the French Alps for example; Etchevers (2000)], but do not measure SWE: a realistic density simulation makes the comparison between simulated snow depth with observed depth more consistent. The relatively simple ISBA-FR scheme imposes an upper limit on the density that is too low for the CdP site, so that the snow depth was systematically overestimated during the latter part of the snow season because of underestimates of the snow density. However, note that depth is only a diagnostic in ISBA-FR and is less important than the SWE in terms of hydrological behavior.

The three schemes were used with the default or baseline snow parameter values taken from the literature (with no additional tuning), given that site-specific snow-model calibration parameters would probably be difficult to apply for a simulation with an atmospheric model. Loth and Graf (1998b) obtained reasonable simulations for several sites with contrasting climates (including (dP) using the same basic physical parameterization schemes (and empirical constants) used by ISBA-ES, so it is possible that these parameters can be applied successfully to many different climate conditions (which would ease implementation of such a scheme into an atmospheric model).

There are considerable differences in computational requirements among the three models (last row, Table 1). CROCUS requires roughly 5 times more computer time than ISBA-FR for simulating an annual cycle on a Hewlett-Packard computer workstation. ISBA-ES takes approximately the same amount of time as the ISBA soil-vegetation module (slightly less than double the time of ISBA-FR). This increase in expense is likely justified by the more realistic snow density, depth, and ripening simulated by ISBA-ES.

More complex physics does not necessarily mean that coupled atmospheric simulations will be improved, given existing biases resulting from other aspects of the parent atmospheric model. Also, improvements in microscale and mesoscale simulations that use prescribed atmospheric forcing cannot always be extrapolated to atmospheric or hydrological simulations, because of the lack of feedbacks between the surface and the atmosphere and scaling issues related to model parameterizations (FSCA for example). However, local-scale studies are useful in evaluating basic scheme behavior in terms of comparison with observational datasets (which are typically at this scale). For example, the Snow Model 
Intercomparison Project (Essery et al. 1999) will address some of the issues discussed in this paper using schemes having a wide range of complexity and for several distinctly different climates at the local scale. Currently, tests are being carried out with ISBA-ES coupled to a distributed hydrological model, and the impact of snow physics on simulated river discharge is being evaluated for a multiyear period. Additional testing will have to be done in a fully coupled mode to determine the impact and cost-efficiency of the new snow scheme in an atmospheric model.

Acknowledgments. The authors are grateful to Herve Douville, Eva Kowalczyk, Andrew Slater, Florence Habets, and Valery Masson for useful discussions related to this research. The lead author also thanks Eric Martin and the people at CEN for their hospitality and assistance during a one-week stay. Also, we thank Joel Noilhan for supporting this research. Last, we thank three anonymous reviewers for their help in improving this manuscript. This research was supported by a grant from EGIDE (Centre Francais pour l'Accueil et les Echanges Internationaux).

\section{APPENDIX}

\section{Solution Procedure for ISBA-ES}

The basic solution procedure for each ISBA-ES time step is described below.

1) At the beginning of time step, $H_{s i}, \rho_{s i}$, and $D_{s i}$ are used to diagnose $T_{s i}$ and $W_{l i}$ [Eq. (7)].

2) Snowfall mass and heat content are added to the uppermost snow layer, and $\rho_{s 1}, D_{s 1}, T_{s 1}$, and $W_{l 1}$ are updated accordingly. Snowfall is assumed to have the same temperature as the uppermost snow layer upon reaching the surface; therefore the advective heat flux from snowfall can be neglected (in the surface energy budget).

3) Settling is calculated [Eq. (4)], and $\rho_{s i}$ and $D_{s i}$ are updated. Snow mass and heat content are unaltered.

4) The snow thicknesses are reset [Eqs. (2)-(3)] and the vertical profiles of mass and heat are redistributed while conserving the total snowpack mass and heat.

5) Shortwave radiation transmission $Q_{s i}$ [Eq. (11)] and surface snow albedo $\alpha_{n}$ [Eq. (13)] are calculated along with the snow thermal conductivity $\Lambda_{s i}$.

6) The linearized system of equations is solved simultaneously [Eq. (8)] to estimate the preliminary profile of $T_{s i}$ and the surface fluxes $G_{s 0}$ [Eq. (14)].

7) If melting occurs, the surface energy budget and fluxes are recalculated assuming an updated uppermost snow-layer temperature at the freezing point $\left(T_{f}\right)$. The lower two snow-layer temperatures are also recalculated assuming $T_{s 1}=T_{f}$.

8) Phase changes $F_{s i}$, water flow $R_{l i}$, and changes in liquid water storage [Eq. (22)] are evaluated. Profiles of $T_{s i}, W_{l i}, \rho_{s i}$, and $D_{s i}$ are updated.
9) The heat content $H_{s i}$ is updated from the profiles of $T_{s i}, W_{l i}, \rho_{s i}$, and $D_{s i}[$ Eq. (7)] and is saved for the next time step along with the updated snow albedo and the profiles of $\rho_{s i}$ and $D_{s i}$. Snow surface fluxes (Eq. 14), runoff $\left(R_{I N}\right)$, and the heat flux at the snowsoil-vegetation interface are output.

\section{REFERENCES}

Anderson, E. A., 1976: A point energy and mass balance model of a snow cover. NOAA Tech. Rep. NWS 19, 150 pp.

Bader, H. P., 1992: Modeling temperature distribution, energy and mass flow in a phase-changing snowpack. I: Model and case studies. Cold Reg. Sci. Technol., 20, 157-181.

Baker, D. G., D. L. Ruschy, and D. B. Wall, 1990: The albedo decay of prairie snows. J. Appl. Meteor., 29, 179-187.

Bohren, C. F., and B. R. Barkstrom, 1974: Theory of the optical properties of snow. J. Geophys. Res., 79, 4527-4535.

Boone, A., 2000: Modélisation des processus hydrologiques dans le schéma de surface ISBA: Inclusion d'un réservoir hydrologique, inclusion du gel et modélisation de la neige (Modeling hydrological processes in the land-surface scheme ISBA: Inclusion of a hydrological reservoir, incorporation of soil ice and snow modeling). Ph.D. thesis, University Paul Sabatier, Toulouse, France, $252 \mathrm{pp}$.

- J.-C. Calvet, and J. Noilhan, 1999: Inclusion of a third soil layer in a land-surface scheme using the force-restore method. J. Appl. Meteor., 38, 1611-1630.

- V. Masson, T. Meyers, and J. Noilhan, 2000: The influence of the inclusion of soil freezing on simulations by a soil-atmosphere transfer scheme. J. Appl. Meteor., 39, 1544-1569.

Brun, E., E. Martin, V. Simon, C. Gendre, and C. Coleou, 1989: An energy and mass balance model of snow cover suitable for operational avalanche forecasting. J. Glaciol., 35, 333-342.

_, P. David, M. Sudul, and G. Brunot, 1992: A numerical model to simulate snow cover stratigraphy for operational avalanche forecasting. J. Glaciol., 38, 13-22.

- E. Martin, and V. Spiridonov, 1997: The coupling of a multilayered snow model with a GCM. Ann. Glaciol., 25, 66-72.

Deardorff, J. W., 1977: A parameterization of ground surface moisture content for use in atmospheric prediction models. J. Appl. Meteor., 16, 1182-1185.

_ 1978: Efficient prediction of ground surface temperature and moisture with inclusion of a layer of vegetation. J. Geophys. Res., 83, 1889-1903.

Derbyshire, S. H., 1999: Boundary-layer decoupling over cold surfaces as a physical boundary-instability. Bound.-Layer Meteor., 90, 297-325.

Dickinson, R. E., 1988: The force-restore model for surface temperatures and its generalizations. J. Climate, 1, 1086-1097.

Dirmeyer, P. A., 1997: The Global Soil Wetness Project, GEWEX News, 7, 3-6.

Douville, H., and J.-F. Royer, 1996: Sensitivity of the Asian summer monsoon to an anomalous Eurasian snow cover within the Météo-France GCM. Climate Dyn., 12, 449-466.

, and - 1997: Influence of the temperate and boreal forests on the Northern Hemisphere climate in the Météo-France climate model. Climate Dyn., 13, 57-74.

_ _ _ and J.-F. Mahfouf, 1995a: A new snow parameterization for the Météo-France climate model. Part 1: Validation in standalone experiments. Climate Dyn., 12, 21-35.

,$- \ldots$, and $-1995 \mathrm{~b}$ : A new snow parameterization for the Météo-France climate model. Part 2: Validation in a 3-D GCM experiment. Climate Dyn., 12, 37-52.

Essery, R., E. Martin, H. Douville, A. Fernández, and E. Brun, 1999: A comparison of four snow models using observations from an alpine site. Climate Dyn., 15, 583-593.

Etchevers, P., 2000: Modélization du cycle continental de l'eau á 
l'échelle régional: Impact de la modélization de l'enneigement sur l'hydrologie du bassin versant du Rhône (Modeling the continental water cycle at a regional scale: Impact of the snow simulation on the hydrology of the Rhone basin). Ph.D. thesis, University Paul Sabatier, Töulouse, France, 361 pp.

- H. Douville, and E. Martin, 1999: Simulation of the Northern Hemisphere snow cover. IAHS Pub. No. 256, 3-10.

Giard, D., and E. Bazile, 2000: Implementation of a new assimilation scheme for soil and surface variables in a global NWP model. Mon. Wea. Rev., 128, 997-1015.

Habets, F., R. Etchevers, C. Golaz, E. Leblois, E. Ledoux, E. Martin, J. Noilhan, and C. Ottlé, 1999: Simulation of the water budget and the river flows of the Rhone basin. J. Geophys. Res., 104, 31 145-31 172.

Hardy, J. P., R. E. Davis, R. Jordan, X. Li, C. Woodcock, W. Ni, and J. C. McKenzie, 1997: Snow ablation modeling at the stand scale in a boreal jack pine forest. J. Geophys. Res., 102, 29 397-29 405.

Henderson-Sellers, A., A. Pitman, P. Love, P. Irannejad, and T. Chen, 1995: the Project for the Intercomparison of Land-Surface Parameterization Schemes (PILPS): Phases 2 and 3. Bull. Amer. Meteor. Soc., 94, 489-503.

Jin, J., X. Gao, Z.-L. Yang, R. C. Bales, S. Sorooshian, and R. E. Dickinson, 1999: Comparative analyses of physically based snow melt models for climate simulations. J. Climate, 12, 26432657.

Jordan, R., 1991: A one-dimensional temperature model for a snow cover. CRREL Special Rep. 91-1b, Cold Regions Research and Engineering Laboratory, Hanover, NH, 49 pp.

- E. L Andreas, and A. P. Makshatas, 1999: Heat budget of snowcovered sea ice at North Pole 4. J. Geophys. Res., 104, 77857806.

Kojima, K., 1967: Densification of a seasonal snow cover: Physics of snow and ice. Proc. Int. Conf. Low Temp. Sci., 1 (2), S.929S.952.

Kondo, J., and H. Yamazaki, 1990: A prediction model for snowmelt, snow surface temperature, and freezing depth using a heat balance method. J. Appl. Meteor., 29, 375-384.

Krinner, G., C. Genthon, Z.-X. Lin, and P. Le Van, 1997: Studies of the Antarctic climate with a stretched grid general circulation model. J. Geophys. Res., 102, 13 731-13 745.

Ledoux, E., G. Girard, G. de Marsilly, and J. Deschenes, 1989: Spatially distributed modeling: Conceptual approach, coupling surface water and ground water. Unsaturated Flow Hydrologic Modeling Theory and Practice, X. Morel-Seytoux, Ed., NATO ASI Series, Vol. 275, Kluwer Academic, 435-454.

Lehnings, M., P. Bartlet, and B. Brown, 1998: Operational use of a snowpack model for the avalanche warning service in Switzerland: Model development and first experiences. Nor. Geotech. Inst., 203, 169-174.

Loth, B., and H.-F. Graf, 1998a: Modeling the snow cover in climate studies. Part 1: Long-term integrations under different climatic conditions using a multi-layered snow-cover model. J. Geophys. Res., 103, 11 313-11 327.

, and $-1998 \mathrm{~b}$ : Modeling the snow cover in climate studies. Part 2: Sensitivity to internal snow parameters and interface processes. J. Geophys. Res., 103, 11 329-11340.

, and J. M. Oberhuber, 1993: Snow cover model for global climate simulations. J. Geophys. Res., 98, 10 451-10 464.

Louis, J. F., 1979: A parametric model of vertical eddy fluxes in the atmosphere. Bound.-Layer Meteor., 17, 187-202.

Lynch-Stieglitz, M., 1994: The development and validation of a simple snow model for the GISS GCM. J. Climate, 7, 1842-1855.

Martin, E., and Y. Lejeune, 1998: Turbulent fluxes above the snow surface. Ann. Glaciol., 26, 179-183.

Mellor, M., 1964: Properties of snow. Cold Reg. Sci. Eng. Monogr. No. III-A1, 105 pp.

Nash, J. E., and J. V. Sutcliffe, 1970: River flow forecasting through conceptual models, 1: A discussion of principles. J. Hydrol., 10 (3), 282-290

Noilhan, J., and S. Planton, 1989: A simple parameterization of land surface processes for meteorological models. Mon. Wea. Rev. 117, 536-549.

_ zation scheme. Global Planet. Change, 13, 145-159.

Pahaut, E., 1976: La métamorphose des cristaux de neige (Snow crystal metamorphosis). Monographie de la Météorologie $\mathrm{Na}$ tionale, No. 96, Météo-France, $58 \mathrm{pp}$.

Pitman, A. J., Z.-L. Yang, J. G. Cogley, and A. Henderson-Sellers, 1991: Description of bare essentials of surface transfer for the Bureau of Meteorology Research Centre AGCM. BMRC Res. Rep. 32, 117 pp.

Schlosser, C. A., and Coauthors, 2000: Simulations of a boreal grassland hydrology at Valdai, Russia: PILPS Phase 2(d). Mon. Wea. Rev., 128, 301-321.

Slater, A. G., A. J. Pitman, and C. E. Desborough, 1998: The validation of a snow parameterization designed for use in general circulation models. Int. J. Climatol., 18, 595-617.

Sud, Y. C., and D. M. Mocko, 1999: New snow-physics to complement SSiB, Part I: Design and evaluation with ISLSCP Initiative I datasets. J. Meteor. Soc. Japan, 77 (1B), 335-348.

Sun, S., J. Jin, and Y. Xue, 1999: A simple snow-atmosphere-soil transfer (SAST) model. J. Geophys. Res., 104, 19 587-19 579.

Verseghy, D. L., 1991: CLASS - a Canadian land surface scheme for GCMs. I: Soil model. Int. J. Climatol., 11, 111-133.

Yang, Z.-L., R. E. Dickinson, A. Robock, and K. Y. Vinnikov, 1997: Validation of the snow submodel of the Biosphere-Atmosphere Transfer Scheme with Russian snow cover and meteorological observations data. J. Climate, 10, 353-373.

Yen, Y.-C., 1981: Review of thermal properties of snow, ice and sea ice. CRREL Rep. 81-10, Cold Regions Research and Engineering Laboratory, Hanover, NH, 27 pp. [Available from CRREL, 72 Lyme Rd., Hanover, NH 03755.] 